\title{
Space Weather Effects Produced by the Ring Current Particles
}

\author{
Natalia Ganushkina ${ }^{1,2}(\mathbb{D}) \cdot$ Allison Jaynes $^{3}$. \\ Michael Liemohn²
}

Received: 6 February 2017 / Accepted: 17 August 2017 / Published online: 2 October 2017

(C) The Author(s) 2017. This article is published with open access at Springerlink.com

\begin{abstract}
One of the definitions of space weather describes it as the time-varying space environment that may be hazardous to technological systems in space and/or on the ground and/or endanger human health or life. The ring current has its contributions to space weather effects, both in terms of particles, ions and electrons, which constitute it, and magnetic and electric fields produced and modified by it at the ground and in space. We address the main aspects of the space weather effects from the ring current starting with brief review of ring current discovery and physical processes and the Dst-index and predictions of the ring current and storm occurrence based on it. Special attention is paid to the effects on satellites produced by the ring current electrons. The ring current is responsible for several processes in the other inner magnetosphere populations, such as the plasmasphere and radiation belts which is also described. Finally, we discuss the ring current influence on the ionosphere and the generation of geomagnetically induced currents (GIC).
\end{abstract}

Keywords Inner Earth's magnetosphere · Ring current $\cdot$ Space weather

The Scientific Foundation of Space Weather

Edited by Rudolf von Steiger, Daniel Baker, André Balogh, Tamás Gombosi, Hannu Koskinen and Astrid Veronig

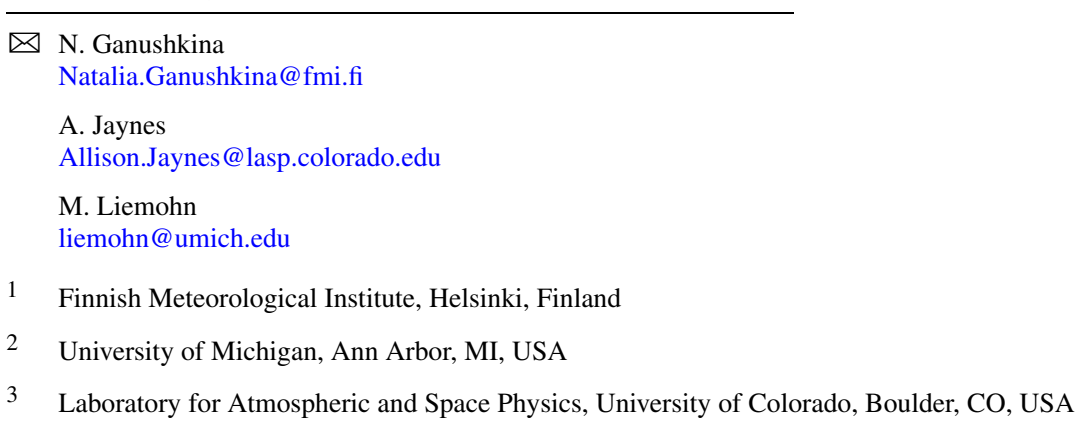




\section{Introduction}

The concept of space weather includes the effects imposed by the time-varying space environment which may be hazardous to technological systems in space and/or on the ground and/or endanger human health or life. One of the important regions where these variations of space environment matter in the Sun-Earth system is the inner Earth's magnetosphere. There a lot of satellites fly and there even rather quiet times are full of dynamical processes. The ring current is one of the populations in the inner magnetosphere consisting of ions and electrons with energies of a few to hundreds of $\mathrm{keV}$. The ring current energies are rather far from the ultra-relativistic energies of "killer electrons" which are especially hazardous and can penetrate even the most protected satellites in space or from the $\mathrm{MeV}$ and $\mathrm{GeV}$ energies of solar energetic particles and galactic cosmic rays which can come very close to the Earth. At the same time, the ring current has rather significant influence in terms of space weather effects.

The ring current has several distinct contributions to the space weather effects, both in terms of particles, ions and electrons, which constitute it, and magnetic and electric fields produced and modified by it at the ground and in space. Ring current is a significant contributor to the Dst-index which, in its turn, can be used as an indicator, a measure and a predictor of geomagnetic storms. Ring current $\mathrm{keV}$ electrons are responsible for surface charging effects on satellites. The ring current dynamics including electric and magnetic field distortions due to this dynamics is tightly related to the radiation belts and plasmasphere populations in the inner magnetosphere. The storm-time ring current has several space weather effects on the ionosphere and thermosphere via influencing on the rearranging of the ionospheric density and heating the thermosphere. The ring current contributes to the Geomagnetically Induced Currents (GIC) effects via its role in the generation of Region 2 field-aligned currents.

There have been numerous reviews on the ring current formation, dynamics and decay and reviews on space weather. While reviews of space weather effects have examined the influence of the ring current, none of them specifically focused on the ring current as a source of space weather effects. The present review addresses the space weather effects from the ring current particles compiled into a single place and avoids repetitions of the general ring current physics. The goal of this review is to stress the importance of the ring current being an inner magnetosphere population with rather moderate energies as compared to the high energy electrons and protons present in the Earth's magnetosphere. The specifics of the ring current particles can result in the space weather effects which are rather extreme without the occurrence of the extreme geomagnetic conditions. Even a presence of a moderate storm is not necessary for significant surface charging event to happen, for example.

This review is an output of "The Scientific Foundation of Space Weather" Workshop which was held during 27 June-1 July 2016 at the International Space Science Institute, Bern, Switzerland. In the following Sect. 2, we start with a very brief review of ring current discovery and physical processes. The Dst-index, the role of the ring current in producing it and predictions of the ring current and storm occurrence based on the Dst-index are presented in Sect. 3. Section 4, the heart of the review, details the space weather effects of the ring current. This begins with the effects on satellites produced by the ring current electrons (Sect. 4.1). The processes in other inner magnetosphere populations, such as the plasmasphere and radiation belts controlled by the ring current, are described in Sect. 4.2. Then, in Sect. 4.3, we discuss the ring current influence on the ionosphere and generation of geomagnetically induced currents (GIC). Finally, the ring current space weather effects are summarized in Sect. 5. 


\section{Ring Current in the Earth's Magnetosphere: Brief Review}

The ring current is one of the oldest concepts in magnetospheric physics (see the historical review by Egeland and Burke 2012). A current flowing around the Earth was first introduced by Störmer (1907) and supported by Schmidt (1917). Chapman and Ferraro (1931, 1941) used a ring current concept for the model of a geomagnetic storm. The ring current can be described in a simplified way as a toroidal shaped electric current, flowing westward around the Earth with variable density at geocentric distances between 2 and $9 R_{E}$. Note that we use "ring current" here with a broad definition that includes any inner magnetospheric westward or eastward current that is either symmetric or not in local time. In fact, the symmetric ring current is often dominated by the partial ring current during magnetic storms (e.g., Takahashi et al. 1990; Liemohn et al. 2001b; Mitchell et al. 2001). Ring current consists of ions and electrons with energies covering the range from about 1 to $400 \mathrm{keV}$. The main ion species are $\mathrm{H}^{+}, \mathrm{O}^{+}$, and $\mathrm{He}^{+}$(see the recent review by Kronberg et al. 2014, where the observations and modeling of ion circulation and effects in the ring current dynamics were presented, and references therein). The intensity of quiet time ring current is about $\sim 1-5 \mathrm{nA} / \mathrm{m}^{2}$ (Lui and Hamilton 1992), which can be as large as $50 \mathrm{nA} / \mathrm{m}^{2}$ during storm times (e.g., Vallat et al. 2005), although there is some debate about this (Liemohn et al. 2016). Although, the early measurements of the ring current particles were made onboard OGO 3 (e.g., Frank 1967), Explorer 45 (e.g., Smith and Hoffman 1974) and CRRES missions (e.g., Grande et al. 1997; Friedel and Korth 1997), the first mission, which clarified the detailed picture of the ring current energy and composition was the AMPTE mission of the late 1980s (e.g., Lui et al. 1987; Lui and Hamilton 1992; De Michelis et al. 1997). Extensive observations of the ring current were done by the most recent Van Allen Probes mission (e.g., Yu et al. 2014; Zhao et al. 2015; Gkioulidou et al. 2016; Kistler et al. 2016; Shi et al. 2016; Menz et al. 2017).

Inner magnetosphere current density can be measured in several ways. They include (1) direct measurements of ion and electron current densities, (2) particle measurements which can provide the plasma pressure and the current itself can be estimated from it, (3) multi-point magnetic field measurements and computing the current density from the curl of magnetic field, (4) remote sensing of energetic neutral atoms (ENAs) emitted from the ring current (for more detailed description of these methods, see the recent reviews by Ganushkina et al. (2015b) and Lühr et al. (2017) and references therein and the commentary by Dunlop et al. 2016).

Two main sources for the ring current particles are the terrestrial ionosphere and the solar wind. Particles from both of them populates the plasma sheet, therefore, it is an important source of the ring current (see the reviews by Ebihara and Ejiri 2003; Daglis 2001, 2006; Kronberg et al. 2014; Ebihara 2016 and references therein). Plasma sheet particles move inward when acted upon by time-varying electromagnetic fields. There are still open questions regarding this process, especially, for storm times, such as, whether substorm-associated magnetic field variations and the associated (inductive) electric fields are necessary for the buildup of the ring current energy density. While there are arguments that large-scale convection alone can account for the ring current increase, other studies have concluded that energization of ring current particles to energies over $100 \mathrm{keV}$ requires smaller-scale, timevarying electric fields (see one of the earliest studies on this subject by Kim et al. 1979 and more recent reviews by Daglis and Kozyra 2002; Ebihara and Ejiri 2003; Kozyra and Liemohn 2003; Ganushkina 2005; Ebihara and Miyoshi 2011; Bourdarie et al. 2016; Ebihara 2016 and references therein).

The concept of the partial ring current and its closure to the ionosphere was suggested by Alfvén in 1950's. One of the earliest observational evidences were given based on OGO 
Inner magnetosphere current density for July 22, 2009 storm
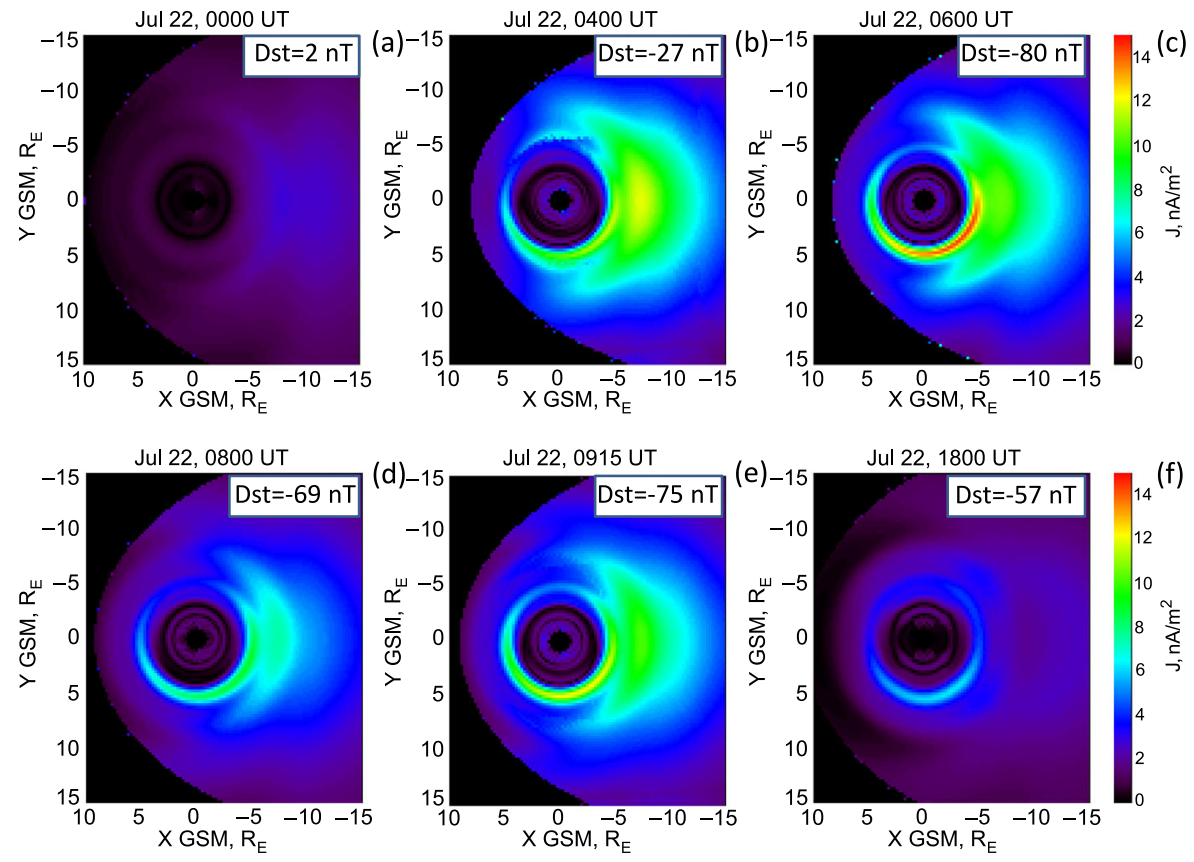

Fig. 1 Evolution of the inner magnetosphere current density in the equatorial plane computed from the curl of the magnetic field modeled with the Tsyganenko T02 global magnetospheric magnetic field model (Tsyganenko 2002a,b) during the storm event on July 22, 2009

3 measurements (Frank 1970). The magnetosphere is essentially asymmetric, compressed by the solar wind dynamic pressure on the dayside, and stretched by the tail current on the night-side. Plasma pressure distribution during disturbed times (storm times) becomes highly asymmetric due to plasma transport and injection from the night-side plasma sheet to the inner magnetosphere. The resulting plasma distribution presents a gradient in the azimuthal direction resulting in the spatial asymmetry of the ring current. The remnant of the perpendicular current must flow along a field line to complete a closure of the current (see the reviews by Ebihara and Ejiri 2003; Kozyra and Liemohn 2003; Ebihara and Miyoshi 2011; Ganushkina et al. 2015b).

Figure 1 presents an illustration on the storm time ring current dynamics. It demonstrates the distribution of the inner magnetosphere current density in the equatorial plane modeled with the Tsyganenko T02 global magnetospheric magnetic field model (Tsyganenko 2002a,b) during the storm event on July 22, 2009. The current densities of the inner magnetosphere current were computed from the curl of the model magnetic field using the Ampère's law with Maxwell's extension. Before the storm at 00 UT when Dst was 2 nT (Fig. 1a), a relatively symmetric ring current can be seen at distances inside $5 R_{E}$ and the near-Earth part of the tail current is present at distances of $10-15 R_{E}$. The Dst becomes negative $(-27 \mathrm{nT})$ at $04 \mathrm{UT}$ and the ring current intensifies with the storm development (Fig. 1b) and becomes asymmetric with its peak shifted duskward at the storm maximum with Dst $=-80 \mathrm{nT}$ (Fig. 1c) at 06 UT. The July 22, 2009 event was a moderate storm. The increased tail current is also evident, although with lower current densities. During the storm recovery phase at $08 \mathrm{UT}(\mathrm{Dst}=-69 \mathrm{nT})$, the ring current density decreases (Fig. 1d), 
but remains asymmetric. There was a second Dst-index drop to about $-75 \mathrm{nT}$ at $0915 \mathrm{UT}$ which can be clearly seen as a new intensification of the ring current (Fig. 1e). The July 22, 2009 storm had a long recovery phase, therefore, close to the end of the day at 18 UT when Dst was $-57 \mathrm{nT}$ (Fig. 1f), the ring current symmetrized but it was still not fully symmetric and its current density decreased but not to the non-disturbed level. This is rather typical storm-time evolution of the ring current.

Ring current ions are lost due to several loss mechanisms (for a recent comprehensive review, see Ebihara and Miyoshi 2011). Charge-exchange between energetic ring current ions and neutral exospheric hydrogen is thought to act as a dominant loss. Through this process, energetic ions colliding with neutral exospheric gas may acquire an electron from the cold neutral atom and become neutralized. Convection outflow occurs when a particle intersects the magnetopause, flows away along magnetosheath magnetic field lines and is lost from the ring current region. In the magnetosphere, the ring current particles experience Coulomb interaction with the thermal plasma in the plasmasphere. They transfer energy to the plasmaspheric plasma due to collisions (Coulomb drag) and some of them are also scattered into the loss cone (their pitch angle changes so that they can be lost in the atmosphere). Although classical collisional processes provide the dominant loss process for ring current ions, two classes of plasma waves are able to interact with ring current ions, namely, electromagnetic ion cyclotron (EMIC) waves and magnetosonic waves. This wave-particle interaction results in the pitch angle scattering which contributes to ion loss, especially during the main phase of a storm. For ring current electrons, charge-exchange is not a loss process. The main losses are Coulomb interactions, convection outflow and wave-particle interactions which are most important. Ring current electrons interact mainly with chorus waves observed outside the plasmasphere and hiss waves inside the plasmasphere.

This section gave a brief introduction to the ring current and the major physical processes controlling it. For additional details of ring current structure, dynamics and physics, please see the numerous reviews cited above.

\section{Dst-Index as a Storm Indicator, Measure and Predictor}

It has long been known that the horizontal component, $H$, of the geomagnetic field is depressed during periods of great magnetic disturbances and that the recovery to its average level is gradual. In 1741 Celsius observed a large magnetic disturbance in Uppsala, Sweden, and Graham observed the same in London, England, simultaneously. These large magnetic field disturbances were called "magnetic storms", and were shown to be non-local. Gauss and Weber founded a network of ground-based magnetic observatories expanded by the British and Russians. It was soon found that magnetic storms are worldwide phenomena. Much later, Akasofu and Chapman (1961), Kamide and Fukushima (1971), Kamide (1974) concluded that the near-equatorial ground disturbance of the magnetic field is a measure of the ring current. Sugiura (1964) and Iyemori (1990) used the averaged magnetic field depression observed at low latitudes to derive the Dst-index.

If the ring current and the Dst-index are directly related and the Dst-index serves as an indicator of a storm activity going on in the magnetosphere, the Dst-index can also serve as a predictor of a future storm occurrence. Therefore, it is useful to predict the Dst-index itself. The ability to predict storm occurrence by predicting of the Dst-index can greatly facilitate the prediction of many storm-related space weather effects. The Dst-index is computed from the observations of the ground-based magnetic field. To be able to achieve the 
goal of Dst-index prediction, models are necessary and these models need to be in the form of operational tools which can be further developed into forecasting tools.

There are several approaches for modeling the Dst-index. One of them is to use models which provide the magnetic field everywhere in the Earth's magnetosphere and on the ground. These models include the semi-empirical models based on the large amount of magnetic field data with specific representations of current systems in them, like the Tsyganenko models (see the review by Tsyganenko 2013 and http://geo.phys.spbu.ru/ tsyganenko/ modeling.html). The most recent model version (Tsyganenko and Andreeva 2015) is intended to forecast the magnetospheric magnetic field using an optimal solar wind coupling function. A very different approach is to use the large volume of magnetic field data for reproducing the detailed structure of the magnetosphere as was done within the TS07 model (Tsyganenko and Sitnov 2007). This approach is somewhat similar to the modelling of the internal geomagnetic field with higher-order harmonics in the scalar potential expansion and it is based on extensible high-resolution expansions for the field of the equatorial current sheet. Early models of the magnetospheric magnetic field used such a method (for example, Mead and Fairfield 1975). Most recently, Andreeva and Tsyganenko (2016) and Tsyganenko and Andreeva (2016) also developed a model without a priori assumptions about the geometry of the magnetic field sources by splitting the model magnetic field into the toroidal and poloidal parts and then expanding each part into a weighted sum of radial basis functions. The Dst-index from these magnetic field models can be computed following the same procedure as for the real Dst-index using the magnetic field modeled at the locations of real Dst low-latitude stations at the Earth's surface as it is done at the World Data Center for Geomagnetism, Kyoto, Japan (http://wdc.kugi.kyoto-u.ac.jp/dstdir/dst2/onDstindex.html).

Global magnetohydrodynamic (MHD) models provide the magnetic field in the magnetosphere and on the ground and they are also used to compute the Dst-index. The detailed analysis of several MHD models' performance to calculate the Dst-index was presented in the study of Rastätter et al. (2013) which resulted from the 2008-2009 Geospace Environment Modeling (GEM) challenge defined at the 2008 GEM workshop. Two quiet and two disturbed events were selected for modeling. The three-dimensional MHD models of the magnetosphere coupled to an ionosphere electrodynamics solver evaluated were (1) the Space Weather Modeling Framework (SWMF) (Tóth et al. 2005, 2012), (2) the Open Geospace General Circulation Model (OpenGGCM) (Raeder et al. 2001), and (3) the Coupled Magnetosphere-Ionosphere-Thermosphere (CMIT) model, also referred to by the magnetospheric Lyon-Fedder-Mobarry (LFM) component (Lyon et al. 2004; Wiltberger et al. 2004). The contributions from the magnetospheric and ionospheric currents were taken into account in the Biot-Savart's integration for the approximation of the Dst-index by the North-South component of the perturbation magnetic field $\delta B_{Z}$ (in SM coordinates) at the Earth's center location (for details, see Rastätter et al. 2013). Another challenge was focused on the reproducing the magnetic field variations at the ground-based stations (Pulkkinen et al. 2010, 2011, 2013; Rastätter et al. 2014). As a result of these challenges, the NOAA Space Weather Prediction Center (SWPC) added the SWMF to the operational forecasting tools. The real-time Dst-index together with the observed one is displayed at http://www.swpc.noaa.gov/products/geospace-global-geomagnetic-activity-plot. None of the other models are operational at present.

Another type of tools is particle, or kinetic, models (brief descriptions of the existing ring current models are give below in Sect. 4.1). From kinetic models, the Dst-index is very often obtained using the Dessler-Parker-Sckopke (DPS) relationship (Dessler and Parker 1959; Sckopke 1966). The DPS relation connects the total energy in the ring current and the change in the ground magnetic field strength. This perturbation can be considered as a rough 
equivalent to the Dst-index if it is assumed (Carovillano and Siscoe 1973) that it is close to the perturbation averaged around the equator of the Earth. The DPS relation was used in numerous studies for Dst-index estimates from modeling and observations and related ring current dynamics (e.g., Greenspan and Hamilton 2000; Ebihara and Ejiri 2000; Fok et al. 2001b; Jordanova et al. 2012; Ganushkina et al. 2012; Katus et al. 2015; Zhao et al. 2015). However, the Dst-index contains contributions from many other sources than the azimuthally symmetric ring current and their contributions can be significant or even largest during disturbed conditions. The suggested magnetospheric sources include (1) magnetopause currents, (2) cross-tail current, (3) partial ring current, and even (4) substorm current wedge (see the review by Maltsev 2004 and references therein) and also studies by Friedrich et al. (1999), Munsami (2000), Ohtani et al. (2001), Liemohn et al. (2001a,b), Liemohn (2003), Ganushkina et al. (2004, 2010), Kalegaev et al. (2005). The magnetic field measured on the ground contains contributions from all current systems and there is no other way to separate them but to use magnetospheric models. The 2008-2009 GEM Dst challenge (Rastätter et al. 2013), in addition to MHD models, included two kinetic ring current models, Ring Current-Atmosphere Interactions Model with Self-Consistent Magnetic Field (RAM-SCB) (Jordanova et al. 2010; Yu et al. 2011) and the Rice Convection Model (RCM) (Toffoletto et al. 2003). The Dst-index from these models was estimated by the DPS relation.

In addition to the DPS relation, the Biot-Savart's law is used to calculate the magnetic disturbance parallel to the Earth's dipole at the center of the earth induced by the azimuthal current component given by the modeled magnetospheric currents within the modeling region. Calculating the model Dst-index by the Biot-Savart's law instead of the DPS relation in nondipolar magnetic field gives larger and more realistic values, since, for example, the effect from the near-Earth tail current is included by the presence of the stretched magnetic field lines (e.g., Liemohn 2003; Ganushkina et al. 2012; Jordanova et al. 2012). None of the kinetic models with the Dst-index as an output is operational and run online in real-time. The main challenge for predicting of the Dst-index and, subsequently, storm occurrence and strength is the absence of reliable predictions of Interplanetary Magnetic Field (IMF) and solar wind parameters, days in advance. These parameters are the main drivers of global empirical and MHD magnetospheric models and kinetic magnetospheric models.

There is also a very different way to predict the Dst-index which does not include any magnetospheric modeling. Different kinds of empirical relations were obtained for the solar wind parameters and the Dst-index. One of the earliest is the relation between changes in Dst-index and the rate of ring current injection as a function of a delayed and filtered solar wind electric field and solar wind dynamic pressure derived by Burton et al. (1975). Following Burton et al. (1975), further corrections and improvements using general relation between the energy balance for the ring current given as the rate of energy input into the ring current and the decay time and DPS relation were done in later studies (e.g., Murayama 1986; Gonzalez et al. 1994; Thomsen et al. 1998; Klimas et al. 1998; Fenrich and Luhmann 1998; O'Brien and McPherron 2000; Wang et al. 2003). The model of this type which is run online in real time is the Dst forecast model by Temerin and $\mathrm{Li}$ (2006) at the Laboratory for Atmospheric and Space Physics (LASP, USA) (http://lasp.colorado.edu/space_weather/dsttemerin/dsttemerin.html). The Dst-index is calculated as a sum of several terms (Temerin and Li 2002, 2006). The first three terms are similar that their driver terms depend strongly on a negative IMF $B_{Z}$-component. They differ from each other by their decay terms. The next term is the pressure term which is proportional to the square root of the solar wind dynamic pressure and it is usually assumed to represent the magnetopause currents. The direct IMF $B_{Z}$ term depends on the angle of 
the dipole with respect to the solar wind velocity. The last term in the offset term which does not depend on the IMF and solar wind parameters and can compensate for a portion of the secular and annual variation in the Dst index.

Other techniques for Dst-index predictions include the usage of neural networks, with delayed inputs, with feed-back connections (e.g., Lundstedt and Wintoft 1994; Lundstedt et al. 2001; Watanabe et al. 2002; Pallocchia et al. 2006; Bala and Reiff 2012; Dolenko et al. 2014; Lu et al. 2016). Bala and Reiff (2012) use the solar wind-magnetosphere coupling function, the Boyle index (Boyle et al. 1997), which is an empirical approximation for the polar cap potential dependent on solar wind parameters, as basis functions to train an artificial neural network to predict the Dst-index. These predictions are shown in real time at http://mms.rice.edu/realtime/forecast.html as 1, 3, and 6 hours ahead. Another operational model is the Lund Dst model (Lundstedt et al. 2001, 2002) run at the Swedish Institute of Space Physics (IRF-Lund, Sweden) at http://www.irfl.lu.se/rwc/dst/. This model is also based on a recurrent neural network that has been optimized to be as small as possible without degrading the accuracy and it is driven by the hourly averages of the IMF $B_{Z}$-component, solar wind number density and velocity. A similar approach is used for the Dst-index predictions (Dolenko et al. 2014) available at the Skobeltsyn Institute of Nuclear Physics Moscow State University (SINP MSU, Russia) at http://swx.sinp.msu.ru/models/dst.php?gcm=1.

Yet another method includes the models based on linear moving average (MA) filters or linear auto-regressive moving average (ARMA) filters, or similar (Vassiliadis et al. 1999) and the nonlinear auto-regressive moving average model with exogenous inputs (NARMAX) applied to Dst-index (Boynton et al. 2011a; Beharrell and Honary 2016). For example, the NARMAX algorithm (Leontaritis and Billings 1985a,b) is an advanced system identification technique, similar to neural networks, which can be applied for linear and non-linear systems with physically interpretable parameters. Boaghe et al. (2001) applied the NARMAX algorithm and derived a model for the Dst-index using $v B s$ with $\mathrm{v}$ as the solar wind velocity and Bs as the southward IMF component as the input. Boynton et al. (2011a) developed a model for the Dst-index using NARMAX with a different coupling function according to Boynton et al. (2011b) as an input. The advantage of this type of models is that the output of the model at a specific time can be represented by rather simple polynomial function of the previous values of inputs, outputs, and error terms (Beharrell and Honary 2016). At present, these types of models are in great demand, since they can give exact (though perhaps not always accurate) values at some time moments in a future.

Ji et al. (2012) compared the outputs from six Dst-index forecast models during intense geomagnetic storms, namely, Burton et al. (1975), Fenrich and Luhmann (1998), O'Brien and McPherron (2000), Wang et al. (2003), Temerin and Li (2006), and Boynton et al. (2011a) models. They found that the Temerin and Li (2006) model gives most reasonable results. The 2008-2009 GEM Dst challenge (Rastätter et al. 2013) also included Burton-type representations (Burton et al. 1975; Murayama 1986), NARMAX model (Boynton et al. 2011a), and Rice Dst model (Bala and Reiff 2012). All of the models showed very reasonable results, NARMAX model (Boynton et al. 2011a) was specifically mentioned.

This brief over-review of Dst prediction methods is indented to give readers an understanding of the various types of models in existence and, in particular, those running online and in real time. These models can be used as an estimate of ring current intensity and, therefore, the severity of the possible space weather effects of the ring current, which will now be discussed. 


\section{Space Weather Effects Related to the Ring Current}

\subsection{Ring Current Electrons and Effects on Satellites}

Electrons with energies less than $100 \mathrm{keV}$ are one of the important constituents of the ring current. Their contribution has been studied starting from the early observations of the ring current. Based on the analysis of the low-energy $(<50 \mathrm{keV})$ electron and proton fluxes onboard the OGO 3 satellite, Frank (1967) showed that the electron component may provide about $25 \%$ of the ring current energy during storm times. Liu et al. (2005) analyzed Explorer 45 electron data for energies from 1 to $200 \mathrm{keV}$ and found the electron contribution of about $7.5 \%$ during quiet time and about $19 \%$ during storm time. Contribution of electrons to the ring current energy content based on the recent Van Allen Probes measurements was estimated to be about $10 \%$ of the ions during storm main phase (e.g., Zhao et al. 2016).

The electron fluxes at these keV energies vary significantly with the current activity on the scale of minutes or even shorter. They can be responsible for surface charging effects which is a serious risk for satellites (e.g., Garrett 1981; Lanzerotti et al. 1998; Koons et al. 1999; Whipple 1981; Davis et al. 2008). The electrons with energies of 10's of keV do not penetrate deep into the satellite materials but stay near the surface. Secondary electrons are generated due to the interactions between the surface materials and both the incident plasma and the solar UV. The satellite's surface materials will be charged in order to have the zero net current between the surfaces and the plasma. Therefore, the surface will have nonzero voltages. Usually, the sunlit areas of the satellite's surface are positive and the shadowed areas are negative. For the conducting surfaces, the potential of the surface is uniform for reaching the equilibrium for zero net current. For insulating materials, this equilibrium can be only on several points on the surface.

Electrons have higher speeds, so they constitute the main source of initial plasma current to a satellite. The currents of photo and secondary electrons from a surface are often higher than the plasma electron current to it. If the average electron energy in the surrounding plasma is larger than $1 \mathrm{keV}$, the regions of a satellite in shadows will be charged negative to significant potentials (several kilovolts). In the dense plasma also the sunlit regions of a satellite can charge to significant levels. Secondary and photoelectron currents are different for different materials. Therefore, there is a wide range of surface potentials. The differences in potential between adjacent materials can cause the local electrical stress resulting in vacuum arcs. Surface materials can also discharge into space or to structure ground. The resulting electrostatic discharge (ESD) currents can electromagnetically couple into electronic circuits and subsystems, causing damage.

Typically, most satellite anomalies due to surface charging at geostationary orbit occur at night and early dawn (e.g., Fennell et al. 2001; Gubby and Evans 2002; O'Brien 2009). During substorms, a hot plasma is injected from the magnetotail into the nightside inner regions. They perform the gradient and curvature drifts towards dawn. These newly injected electrons can cause significant changes in the satellite charging levels.

When an anomaly occurs, the radiation environment may be more extreme than that given by the specification models used for design. However, data may not be available at the location of the satellite to fully determine the cause of the anomaly. Therefore, there is a need for physical models with the correct dynamical behavior that can be used to reconstruct the radiation environment. To determine the impact of an extreme space weather event on satellites, we need to define the space radiation environment for different orbits. This can be done by using a combination of physical models and in-situ observations. 
Significant surface charging events can happen during rather undisturbed conditions, like small, isolated substorms (e.g., Ganushkina et al. 2013; Matéo-Vélez et al. 2016). Occurrence of a storm, even a moderate one, can be not directly related to the occurrence of the surface charging. The electron flux at the $\mathrm{keV}$ energies is largely determined by convective (Korth et al. 1999; Friedel et al. 2001; Thomsen et al. 2002; Elkington et al. 2004; Miyoshi et al. 2006; Kurita et al. 2011; Jordanova et al. 2016) and substorm-associated (Vakulin et al. 1988; Grafodatskiy et al. 1987; Degtyarev et al. 1990; Fok et al. 2001a; Khazanov et al. 2004; Kozelova et al. 2006; Ganushkina et al. 2013; Yu et al. 2014; Turner et al. 2015) electric fields. Since it varies on short time scales, it is not possible to average the keV electron fluxes over an orbit/day/hour as it can be done for higher energies, like MeVs. This makes the modeling of $\mathrm{keV}$ electron flux variations very challenging.

When modeling using physics-based models (kinetic models for the ring current), it is necessary to follow keV electrons in large-scale, time-varying magnetic and electric fields. Even though there exist several models, the correct models for these fields are extremely hard to develop. Electrons in the inner regions come from the plasma sheet where specification of a realistic boundary conditions is very nontrivial. The question of how to introduce losses for low energy electrons is still open. Here, the issue about the importance of other waves, apart from chorus and hiss, in the pitch angle scattering resulting from wave-particle interactions is still unclear. Finally, the most important factor in the electron dynamics is substorms which play a significant role in $\mathrm{keV}$ electron transport and energy increase. Their proper modeling has not been done yet.

Fluxes of low-energy electrons have been modeled in several studies as a part of ring current simulations. One of the widely used inner magnetosphere models is the ring currentatmosphere interactions model (RAM) (Jordanova et al. 1996) mentioned above in Sect. 3. Jordanova and Miyoshi (2005), Miyoshi et al. (2006), and, more recently, Jordanova et al. (2014) extended the RAM model to relativistic energies and electrons investigating the effect of magnetospheric convection and radial diffusion during the October 2001 geomagnetic storm and later for October 2012 storm (Jordanova et al. 2016). This model is part of the SHIELDS project of Los Alamos National Laboratory (http://www.lanl.gov/projects/ shields/index.php).

Chen et al. (2006) performed magnetically self-consistent ring current simulations during the 19 October 1998 storm calculating the ion and electron transport in the equatorial plane using the kinetic proton and electron drift-loss model (Chen et al. 1994) coupled to the force-balanced representation of the magnetic field intensity (Chen et al. 2005).

Another widely used inner magnetosphere model is the Rice Convection Model (RCM), also mentioned above in Sect. 3, which describes plasma electrodynamics in the inner and middle magnetosphere and its coupling to the ionosphere (see the review by Toffoletto et al. 2003 and references therein). The Rice Convection Model Equilibrium (RCM-E) (Lemon et al. 2004) combines the drift physics computing the bounce-averaged relativistic drifts of isotropic electrons and ions with a model of equilibrium magnetic field in a force balance with the RCM-computed pressures. In addition to magnetic self-consistency, the particle transport is also self-consistent with the electric field. This model was used for the assessing of the different electron loss models for the model's ability to reproduce the observed electron fluxes of $1.2 \mathrm{keV}$ to $925 \mathrm{keV}$ measured by LANL 1994-084 satellite during the large 10 August 2000 magnetic storm (Chen et al. 2015).

These studies were focused on the application to specific events. The models are not run online in real time. Taking into account the space weather effects requires models run in near real time, when no changes can be made and the models are supposed to perform reasonably well for wide range of geomagnetic conditions, not just for specific storm events. 
The model which is run online at the Community Coordinated Modeling Center (CCMC) (http://ccmc.gsfc.nasa.gov/index.php) in near real time is Fok Ring Current Model (FRC). This is a bounce-averaged kinetic model which calculates the temporal and spatial variation of the phase space density of ring current species, including electrons in the energy range of 1-300 keV (Fok and Moore 1997; Fok et al. 1999, 2001b). The model inputs are the solar wind driven outputs of the global MHD modeling provided in near real time by the Space Weather Modeling Framework (Tóth et al. 2005, 2012). 3D magnetic fields, as well as equatorial plasma density and temperature are obtained from the global magnetosphere SWMF GM/BATSRUS model (Powell et al. 1999; De Zeeuw et al. 2000) and 2D ionospheric height-integrated potentials are given by the ionospheric electrodynamics SWMF IE/RIM model (Ridley et al. 2001, 2004). Equatorial plasma density and temperature are used to set the boundary conditions in the plasma sheet for electrons, which move inward in the provided magnetic and computed from the ionospheric potentials electric fields. The model output given as the electron fluxes as functions of time, energy and pitch angle for different $\mathrm{keV}$ energy ranges in the equatorial plane is presented. At the same time, no real time comparison with the observations is shown.

A variation of the FRC model is the Comprehensive Inner-Magnetosphere Ionosphere (CIMI) model which also calculates the temporal and spatial variation of the phase space density of electrons in the energy range of 1-4000 keV (Fok et al. 2011, 2014). Instead of MHD-related inputs, this model has different inputs based on empirical models. For 3D magnetic fields, it employs Tsyganenko magnetospheric magnetic field T96 (Tsyganenko 1995) and T04 (Tsyganenko and Sitnov 2005) models. Weimer (2005) representation for ionospheric electric potentials at the model's poleward boundary at $70.3^{\circ}$ magnetic latitude is used to set up the electric field. The initial distribution for electrons is set according to the empirical model of AE8 (Vette 1991). Boundary conditions in the plasma sheet are specified by the empirical plasma sheet models (Ebihara and Ejiri 2000; Borovsky et al. 1998; Tsyganenko and Mukai 2003). This model also provides the equatorial electron fluxes as functions of time, energy and pitch angle but it is not run in real time with no comparison with the observations.

The model which runs online in real time and which outputs are directly compared to the real time observations for low energy $(<200 \mathrm{keV})$ electrons is Inner Magnetosphere Particle Transport and Acceleration model (IMPTAM) (Ganushkina et al. 2013, 2014, 2015a). IMPTAM operates online (imptam.fmi.fi) under the completed FP7 SPACECAST and SPACESTORM projects (http://fp7-spacecast.eu, http://www.spacestorm.eu/) funded by the European Union Seventh Framework Programme and under the on-going H2020 PROGRESS project (https://ssg.group.shef.ac.uk/progress2/html/) funded by the European Union's Horizon 2020 research and innovation programme. Its mirror site is also at the Center for Space Environment Modeling (CSEM) at the University of Michigan (http://csem.engin.umich. edu/tools/imptam). The driving parameters are determined by the models used in IMPTAM. The T96 model (Tsyganenko 1995) is used for the external magnetic field and the Boyle et al. (1997) polar cap potential mapped to the magnetosphere is used for the electric field. The model boundary is set at $10 R_{E}$ as a kappa electron distribution function with parameters given by the Tsyganenko and Mukai (2003) empirical model with necessary scaling for electrons. The solar wind and IMF parameters which drive the IMPTAM are solar wind density $N_{S W}$, dynamics pressure $P_{S W}$, velocity $V_{S W}$, IMF $B_{Y}, B_{Z}$, and total IMF strength. The model provides the low energy electron flux at all L-shells and at all satellite orbits, when necessary. Real time geostationary GOES 13 or GOES 15 (whenever which available) MAGED data on electron fluxes at three energies (40, 75, and $150 \mathrm{keV}$ ) are used for comparison and validation of IMPTAM running online (Ganushkina et al. 2015a). IMPTAM provides nowcast of $\mathrm{keV}$ electrons comparable to the observations. 
A purely empirical model for ion flux and electron flux in the energy range $\sim 1 \mathrm{eV}$ to $\sim 40 \mathrm{keV}$ at geosynchronous orbit (GEO) was developed by Denton et al. $(2015,2016$, 2017) based on a total of 82 satellite-years of observations from the Magnetospheric Plasma Analyzer instruments on Los Alamos National Laboratory satellites (http://gemelli. spacescience.org/mdenton/). The model provides the electron flux values at any energy and local time for given values of the 3-hour $\mathrm{Kp}$-index or solar wind electric field $\left(-v B_{z}\right)$. The $\mathrm{Kp}$ version of the model also provides flux values for given values of the daily F10.7 index. The limited number of driving parameters makes this model not suitable for fast variations of $\mathrm{keV}$ electrons. Even though the model is called empirical, no equations are provided which can be easily used to relate electron flux at a specific energy with the driving parameters.

A very different approach is used in the SNB3GEO models (Balikhin et al. 2011; Boynton et al. 2015, 2016) based on Multi-Input Single-Output (MISO) Nonlinear AutoRegressive Moving Average with eXogenous inputs (NARMAX) methodologies (Leontaritis and Billings 1985a,b). In the applied system identification approach, models are automatically deduced from input-output data by the system identification algorithms. NARMAX is capable of modeling nonlinear dynamics within the system and can provide a simple polynomial function with intuitive understanding of how the inputs change the output. The model is run online in real time at the University of Sheffield Space Weather Website (http://www.ssg.group.shef.ac.uk/USSW/UOSSW.html) and under the H2020 PROGRESS project (https://ssg.group.shef.ac.uk/progress2/html/index.phtml) funded by the European Union's Horizon 2020 research and innovation programme. The model inputs are the solar wind velocity, density and pressure, the fraction of time that the IMF was southward, the IMF contribution of a solar wind-magnetosphere coupling function following Boynton et al. (2011b) and the Dst-index. The model output is the fluxes for 30-50 keV, 50-100 keV, 100-200 keV, 200-350 keV and 350-600 keV directly compared to the GOES MAGED observations at geostationary orbit. This model also contains a forecast. For low energy electrons, it is not possible to forecast one day ahead because the same day variations in the solar wind affect the current low energy electron flux. Boynton et al. (2016) calculated the past 24 hour averages for each hour and, therefore, the input time lags in the algorithm were shifted hourly, not daily. It is stated that the model provides accurate forecasts with prediction efficiencies ranging between $66.9 \%$ and $82.3 \%$. At the same time, smaller-scale variations are not forecasted but they constitute the most important factor when trying to estimate the surface charging effects from $\mathrm{keV}$ electron variations.

None of the models has explicit representation for substorms which are a crucial factor in the transport and acceleration of keV electrons. There have been several studies aimed at the modeling of electron injections as they are well-known signatures of a substorm in the near-Earth space (Li et al. 1998; Zaharia et al. 2000; Sarris et al. 2002; Gabrielse et al. 2012, 2014, 2016; Ganushkina et al. 2013, 2014). These models give relatively good agreement with the observed dispersionless electron injections at geostationary orbit during specific events (Ingraham et al. 2001; Fok et al. 2001a; Li et al. 2003; Mithaiwala and Horton 2005; Liu et al. 2009). The substorm-associated electromagnetic fields are very complex and their proper representation is still missing from the modeling efforts for $\mathrm{keV}$ electrons in the inner magnetosphere. No technique is implemented yet to include substorm influence on modeled fluxes in real time.

Ring current electrons in the keV energy range represent a real threat to equatorially orbiting spacecraft. In the midnight-to-dawn sector, fresh injections can intensify the lowenergy electron fluxes and cause surface charging, sometimes with detrimental effects. Several models exist which nowcast or forecast these electrons, providing at least some level of awareness about this population. The critical influence of substorms on the near-Earth keV 
electrons, however, has not yet been fully implemented into a real time and online prediction tool.

\subsection{Ring Current and Inner Magnetosphere Populations}

\subsubsection{Ring Current and Radiation Belts}

The ring current is often thought of as a lower-energy part of the outer radiation belt that surrounds Earth in a toroidal shape. However, these are really two distinct populations with very different dynamics and responses to solar wind forcing (e.g. Schulz and Lanzerotti 1974; Liemohn 2006; Reeves et al. 2016). Naturally, there does exist a coupling between the two energy regimes, as they overlap in spatial extent most of the time. In fact, a very significant influence of the ring current on radiation belt losses during the main and recovery phases of geomagnetic storms (e.g. Ukhorskiy et al. 2015).

The first effect is related to the diamagnetic consequences of a partial ring current that develops during storms. Inflation of the near-Earth magnetic field due to ring current changes (e.g. Parker and Stewart 1967; Tsyganenko et al. 2003; Ganushkina et al. 2010) alters the drift paths of the relativistic electrons in the radiation belts, causing the adiabatic "Dst effect" (e.g. Kim and Chan 1997), which can become a real loss of particles at the magnetopause (e.g. West et al. 1972; Hudson et al. 1998; Ukhorskiy et al. 2006). This process has been identified as contributing rapid loss for up to $90 \%$ of the pre-existing population of both radiation belt electrons (100's keV to multi-MeV) energies and energetic ring current protons (100's keV to $>1 \mathrm{MeV}$ ) (Turner et al. 2014).

The second effect is due to pitch angle scattering of relativistic electrons via wave-particle interactions. The notable mode here is electromagnetic ion-cyclotron (EMIC) waves, since these waves are able to very efficiently interact with high-energy radiation belt electrons (Summers et al. 1998; Meredith et al. 2003), and are driven by unstable ring current proton distributions (Anderson and Hamilton 1993). The anisotropy required for EMIC wave growth is fueled by ring current proton injections, which are convected inward to the inner magnetosphere during intervals of enhanced storm and substorm activity (e.g. Young et al. 1981; Jordanova et al. 2001). Recent simulations combined with the data from the Van Allen Probes (Mauk et al. 2013), the mission specifically designed for radiation belts, have demonstrated the dramatic effect on $>1 \mathrm{MeV}$ electron pitch angle distributions that EMIC waves can have (see, for example, Usanova et al. 2014). While this study did not find a clear way for EMIC waves to produce a full dropout of the core electron population, the flux levels were reduced substantially at lower pitch angles, indicating significant precipitation. Electron precipitation can have impacts on human society at the ground level, as well as terrestrial weather and climate systems (e.g. Rodger et al. 2010). Cutting edge models need to incorporate radiation belt losses from both of these effects: loss to the outer boundary of the magnetosphere via magnetopause shadowing and loss from atmospheric precipitation due to EMIC wave scattering.

Radiation belt enhancement and acceleration events are likewise tied to ring current dynamics. Local acceleration can provide significant acceleration of electron populations in the heart of the outer belt. The process is generated by VLF whistler-mode chorus waves, which grow as a result of a temperature anisotropy in few-10s keV electrons (Helliwell 1967) likely caused by substorm injections (Tsurutani and Smith 1974; Meredith et al. 2001). This anisotropic population of ring current energy electrons is often called the "seed" population, wherein the source of the free energy for chorus wave growth is available. Chorus waves interact with "seed" electrons at energies of 10's to 100's of keV through cyclotron resonance 
and can accelerate electrons to very high energies (Kennel and Petschek 1966; Kennel and Thorne 1967; Li et al. 2008, 2012; Thorne 2010). Whistler-mode chorus plays a critical role in accelerating ring current electrons to relativistic energies in the outer belt (Horne et al. 2005; Green 2006; Chen et al. 2007), including to "killer" electron energies that can have disastrous space weather consequences to sensitive systems (Baker 2001; Fennell et al. 2001).

\subsubsection{Ring Current and Plasmasphere}

The ring current overlaps the cold, dense plasmasphere surrounding Earth, with the center peak of the ring current typically co-located with the plasmapause boundary (Kozyra et al. 1997; Burch et al. 2001). The ring current can effect the shape of the plasmasphere (e.g. Goldstein et al. 2003; Liemohn et al. 2004; Gallagher et al. 2005), and the location of the plasmapause boundary, thereby sculpting the energy-dependent radiation belts and influencing electron precipitation to the atmosphere and locations of enhanced spacecraft charging.

Enhanced convection during geomagnetically active times leads to erosion of the plasmasphere such that the boundary contracts throughout local times (e.g. Nishida 1966), although a high-density plume can form on the duskside of Earth (e.g. Brice 1967; Carpenter 1970; Spasojević et al. 2003). Drainage plumes may also form, allowing direct transport of plasmaspheric particles to the outer magnetosphere (Grebowsky 1970; Chen and Wolf 1972; Rasmussen et al. 1993; Goldstein et al. 2004). Additionally, sub-auroral polarization streams (SAPS) can contribute to the erosion of the plasmasphere on very fast timescales (Gonzales et al. 1978; Burke et al. 1998; Foster and Vo 2002; Califf et al. 2016). During storm time, ring current injections influence the near-Earth electric field (Jaggi and Wolf 1973; Fok et al. 2001a) to the extent that the ionospheric convection pattern is affected which has space weather effects on human technologies such as GPS signal processing (Yeh et al. 1991; Foster et al. 2002).

The variation of plasmaspheric dynamics contribute to distinct consequences that effect the ring current population. First is the myriad roles of wave-particle interactions. When the plasmasphere begins to refill after a period of erosion to low radial distances, the outward expansion of the sharp density boundary once it overlaps the inner edge of the ring current can trigger lower hybrid wave growth (Roth and Hudson 1992). These waves can then accelerate low-energy ring current ions. Another effect is the growth of whistler-mode chorus waves much closer to Earth during an eroded plasmasphere, which will both scatter and accelerate a range of ring current electrons and ions. One more effect is the growth of EMIC waves in plasmaspheric plumes (Posch et al. 2010), which are triggered by ring current proton anisotropies. The existence of a high-density plume can encourage EMIC wave growth, which can contribute to losses of the "killer electrons" at ultra-relativistic energies (Horne and Thorne 1998). Finally, VLF hiss waves, which exist inside the dense plasmasphere, can produce a slow and steady loss of ring current electrons and protons (Thorne et al. 1973; Kozyra et al. 1994).

The position of many of these wave-particle interactions depends on the dynamics of the plasmasphere and plasmapause boundary. The location of the plasmasphere therefore effects where in space, and on the ground, many space weather consequences of the ring current are localized. Modeling of the plasmasphere, ring current, and associated plasma waves are essential for comprehensively defining the space weather environment.

\subsection{Ring Current and Ionosphere and Below}

The ring current not only influences the near-Earth magnetosphere with space weather consequences, but also alters the ionosphere and thermosphere. This is done through closure of 
the partial ring current and the generation of strong ionospheric flows. Inner magnetospheric plasma populations are often highly asymmetric in local time during active times, which creates localized pressure peaks and corresponding field aligned currents (FACs) at the two ends of the pressure crescent (Wolf 1970; Fok et al. 2001b; Liemohn et al. 2001a). These region 2 FACs become current source and sink regions in the ionosphere, where horizontal currents flow to close the circuit. The resulting horizontal electric fields in the ionosphere can be drastically different than the "standard" closure of the region 1 FACs, especially near the equatorward edge of the auroral zone and at subauroral latitudes. They are often poleward electric fields associated with a strong westward (sunward) flow in the midlatitude ionosphere. These flows have dramatic consequences for ionospheric density and thermospheric density, temperature, and composition.

\subsubsection{Ring Current and Ionosphere and Thermosphere}

The closure of the ring current FACs through the ionosphere create subauroral polarization streams (SAPS). The term SAPS was first coined by Foster and Burke (2002) to classify the evening-sector increase in electric field equatorward of the electron precipitation boundary. Because the plasma sheet ions drift closer to the Earth in this sector, region 2 FACs enter the ionosphere at a latitude without much ionization from the precipitation of keV-energy electrons. Foster and Vo (2002) and Erickson et al. (2011) presented statistical analyses of these electric fields and ionospheric flows, showing a clear dependence of SAPS intensity and spatial extent with geomagnetic activity. Ridley and Liemohn (2002) showed that they were directly linked to the partial ring current localized pressure peak, and other observations and numerical modeling has confirmed and further quantified this relationship (e.g. Garner et al. 2004; Mishin and Burke 2005; Liemohn et al. 2005; Yu et al. 2015; Yuan et al. 2016; Califf et al. 2016). SAPS are relatively stable during storms, being a persistent feature across the evening sector that can last for many hours (e.g. Huang and Foster 2007) as the hot ions in the inner magnetosphere slowly drift through near-Earth space. However, SAPS also occur during less active times, including isolated substorms (e.g. Karlsson et al. 1998; Wang et al. 2008).

These strong flows greatly perturb the storm-time ionospheric density configuration at midlatitudes. Pintér et al. (2006) showed that SAPS cause significant density depletion in the fast-flow channel. However, just equatorward of the peak of the flow channel, the higher densities from lower latitudes can become entrained in the westward flows, creating storm enhanced density (SED) plumes, which are anomalously high ionospheric electron densities on the dayside at mid-to-high latitudes during storms (e.g. Kelley et al. 2004; Heelis and Coley 2007). Yin et al. (2004) showed that SAPS created a SED over the USA during the 15 July 2000 storm, influencing Global Positioning System (GPS) communications. In fact, total electron content (TEC) maps created from GPS signal processing has been extensively used to quantify the timing and intensity of SEDs (e.g. Bust et al. 2007; Wen et al. 2007; Yizengaw et al. 2007; Basu et al. 2008; Coster and Skone 2009). SEDs have been shown to extend right through the dayside auroral zone into the polar cap, becoming tongues of ionization and, if breaking off, polar cap patches (e.g. Horvath and Lovell 2009, 2015). Interestingly, Sojka et al. (2004) and David et al. (2011) showed that SEDs might actually be a locally produced phenomenon, with the horizontal SAPS flows driving ExB drift in slant paths, suppressing recombination and allowing a new, higher equilibrium density at these locations. Schunk et al. (2012) assessed their online ionospheric prediction model, the Global Assimilation of Ionospheric Measurements (GAIM) model, especially for the low and midlatitude regions. They concluded that a significant part of the error of the results was 
due to uncertain magnetospheric inputs to the code. It is clear that the ionosphere is greatly perturbed by the electric fields related to the closure of the partial ring current with effects at all local times and across a range of latitudes.

The neutral upper atmosphere is also affected by these strong subauroral electric fields. Wang et al. (2011) conducted a statistical study of the influence of SAPS on the thermosphere, finding a $10 \%$ increase in density within the flow channel, presumably from heating. This was further explained with numerical modeling by Wang et al. (2012), who found that SAPS cause increases in global thermospheric temperature, but this effect takes days to fully develop. They also found that SAPS drive large thermospheric zonal winds due to ion-neutral drag. The heating also caused compositional changes to the thermosphere, with upwelling of molecular-rich atmosphere and downwelling of atomic-oxygen-rich gas elsewhere. Mishin et al. (2012) found that SAPS can create atmospheric gravity waves near $300 \mathrm{~km}$ altitude, presumably related to this localized thermospheric density and temperature enhancement.

A final example is Codrescu et al. (2012), who examined real time simulations of the Coupled Thermosphere-Ionosphere Plasmasphere-Electrodynamics model, CTIPe, who compared upper atmospheric neutral mass density results against CHAMP observations. They found that the total amplitude of the perturbations was well captured but the timing was not, indicating that nonlinear feedback in the system, such as that from the ring current, could be crucial in accurately predicting thermospheric space weather effects.

Note that SAPS have been related to the faster, narrower channels of flow known as polarization jets (Galperin et al. 1974) or sub-auroral ion drifts (SAIDs) (Anderson et al. 1993). SAPS, however, are broader in latitude and lower in intensity than these sharp spikes in electric field and ionospheric flow. One hypothesis for the relationship between these phenomena is the localized intensification of the SAPS field as increased temperature enhances the ionospheric recombination rate and lowers the conductivity in the SAPS channel (Wolf et al. 2007).

\subsubsection{Ring Current and GICs}

Geomagnetically induced currents (GIC) (Pirjola 2000; Boteler 2001) can disrupt normal transmission system operations triggering voltage collapse or damage transformers (e.g. Kappenman et al. 1997; Molinski 2002; Wik et al. 2009). The magnitude of GIC flowing in the high-voltage power transmission networks is determined by the horizontal geoelectric field (e.g. Pirjola 2002, 2013). The induced geoelectric field on the ground is mainly controlled by currents in the magnetosphere and ionosphere, and by the conductivity of the Earth (e.g. Pirjola 2000, 2002; Ngwira et al. 2013).

The large-scale electric currents in the ionosphere are coupled to the magnetosphere through field-aligned currents (FACs). The Region 1 currents that reside on open field lines are driven by the solar wind, which acts as a generator (Siscoe et al. 1991) by dayside reconnection. On closed field lines, their formation can be due to processes taking place in either the boundary layer (Lotko et al. 1987) or in the plasma sheet (e.g. Antonova and Ganushkina 1997; Toffoletto et al. 2001).

The Region 2 currents flow at lower latitudes and can be mapped to the ring current region. They are produced by the pressure gradient dynamics in the inner magnetosphere (Vasyliunas 1970; Birmingham 1992; Heinemann 1990; Heinemann and Pontius 1991). Thus, the ring current dynamics contributes to the GIC effects via its role in the generation of Region 2 FACs. Numerous other studies have examined the connection between conductance and the ring current (e.g. Fok et al. 2001b; Jordanova 2003; Sazykin et al. 2002; Khazanov 
et al. 2003; Ebihara et al. 2004; Liemohn et al. 2005), showing that the partial ring current closure can strongly perturb the inner magnetospheric electric fields.

GICs with large amplitudes are of primary concern for high-latitudes but, at the same time, the GICs were recently observed at the magnetically mid- and low-latitudes during storm times (e.g. Kappenman 2003; Trivedi et al. 2007; Marshall et al. 2012; Zhang et al. 2015; Barbosa et al. 2015; Watari 2015). The presence of the enhanced ring current during storms may be directly related to the GIC generation at these latitudes. The exact connection between the storm-time ring current and these subauroral GICs, however, has yet to be fully understood.

The geoelectric field can be computed in different ways but it is necessary to have the ground-based geomagnetic field obtained either from observations (Viljanen et al. 2006; Pulkkinen et al. 2012; Ngwira et al. 2013) or from the first-principles-based MHD modeling of the magnetosphere-ionosphere system as surface variations of magnetic field at the ground-based stations (Pulkkinen et al. 2013; Glocer et al. 2016) and a representative ground conductivity structure (Pirjola 2002). The ring current physics needs to be properly modeled for the geoelectric field calculations, especially during extreme space weather events.

\section{Summary}

The space weather effects from the ring current particles with keV energy range cannot be considered as highly obvious as those from the "killer" electrons or from the solar energetic protons with energies of tens of $\mathrm{MeVs}$ but they are nevertheless quite significant. Figure 2 summarized the space weather effects that can be produced by the ring current. One of the definitions of space weather includes the time-varying conditions in the space environment that may be hazardous to technological systems on the ground. Ring current has a direct influence on the Dst-index which is computed from the ground-based magnetic field observations and which is an indicator of a storm activity. Electrons with energies less than

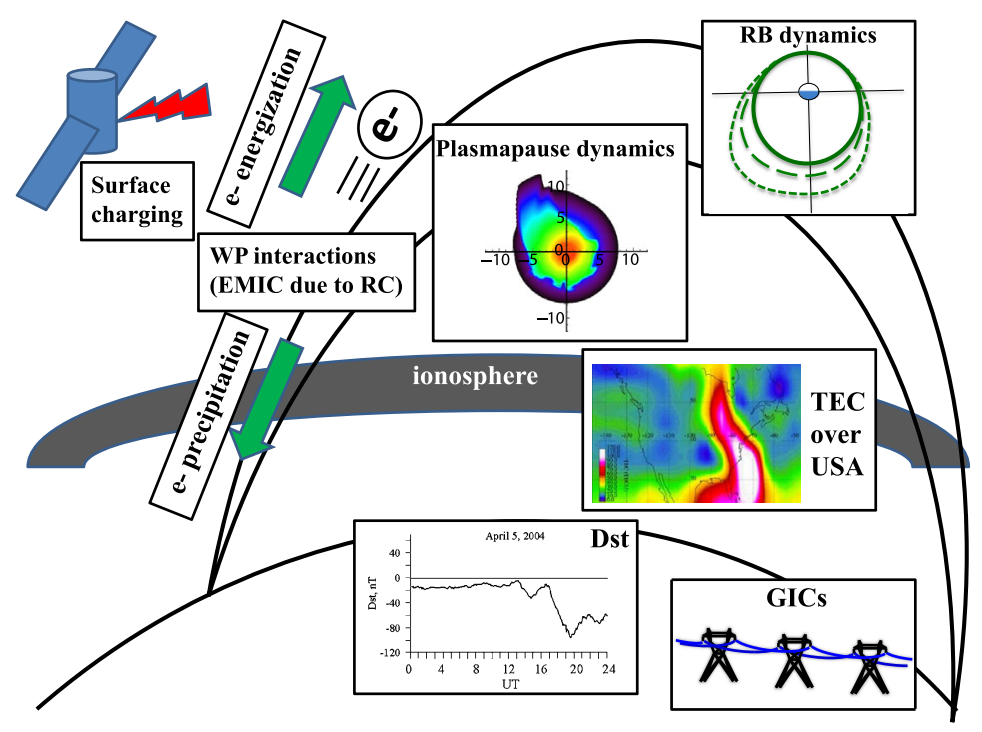

Fig. 2 Space weather effects due to ring current 
$100 \mathrm{keV}$ are one of the important constituents of the ring current. The electron fluxes at these $\mathrm{keV}$ energies vary significantly with the current activity on the scale of minutes or even shorter. The keV electrons do not penetrate deep into the satellite materials but stay near the surface. They can be responsible for surface charging effects which is a serious risk for satellites.

Ring current dynamics are tied to both radiation belt losses and enhancements by affecting the efficiency of magnetopause shadowing and driving various wave-particle interactions. These consequences can be dramatic and impulsive, thereby altering the higher-energy space weather environment suddenly. With the addition of the overlapping plasmasphere, the picture is complicated further. Effective space weather models need to account for the myriad interacting density regimes and particle populations that are related to ring current changes.

The storm-time ring current has several detrimental space weather effects on the ionosphere and thermosphere. The partial ring current closes through the ionosphere, which leads to the SAPS phenomenon of strong westward flows at mid-latitudes. This rearranges the ionospheric density, creating SED plumes across the dayside middle and high latitude regions, extending even over the polar caps. These density enhancements adversely affect GPS signals, resulting in location errors of 50-100 meters during large events. Furthermore, the thermosphere is heated by the SAPS flows, leading to chemistry changes, and thermospheric winds ramp up to match the ionospheric flows during prolonged SAPS intervals.

The ring current contributes to the Geomagnetically Induced Currents effects via its role in the generation of Region 2 FACs. The magnitude of GIC is determined by the horizontal geoelectric field which is mainly controlled by currents in the magnetosphere and ionosphere, and by the conductivity of the Earth. The large-scale electric currents in the ionosphere are coupled to the magnetosphere through field-aligned currents (FACs). The Region 2 currents which can be mapped to the ring current region are generated by the pressure gradient dynamics in the inner magnetosphere.

The dynamics of the ring current is a preeminent factor in space weather forecasting, thereby of critical importance to the health and safety of our spacecraft systems. The ring current does not interact independently and alone, it is tied to the greater system.

Acknowledgements The authors thank the International Space Science Institute (ISSI) in Bern, Switzerland, for the support of the workshop "The Scientific Foundation of Space Weather". N. Ganushkina thanks the ISSI for the support of the international teams on "Analysis of Cluster Inner Magnetosphere Campaign Data, in Application the Dynamics of Waves and Wave-Particle Interaction within the Outer Radiation Belt" and "Ring Current Modeling: Uncommon Assumptions and Common Misconceptions." The research of N. Ganushkina leading to these results was partly funded by the European Union Seventh Framework Programme (FP7/2007-2013) under grant agreement No. 606716 SPACESTORM. The research of N. Ganushkina and M. Liemohn leading to these results was partly funded by the European Union's Horizon 2020 research and innovation programme under grant agreement No. 637302 PROGRESS. Support for M. Liemohn and N. Ganushkina at Michigan was provided by research grants from NASA (NNX14AF34G, NNX14AC02G, and NNX17AB87G) and NSF (AGS-1414517). The work of A. Jaynes was supported by RBSP-ECT funding provided by JHU/APL contract 967399 under NASA's Prime contract NAS5-01072.

Open Access This article is distributed under the terms of the Creative Commons Attribution 4.0 International License (http://creativecommons.org/licenses/by/4.0/), which permits unrestricted use, distribution, and reproduction in any medium, provided you give appropriate credit to the original author(s) and the source, provide a link to the Creative Commons license, and indicate if changes were made.

\section{References}

S.-I. Akasofu, S. Chapman, The ring current, geomagnetic disturbance, and the Van Allen radiation belt. J. Geophys. Res. 66, 1321-1350 (1961) 
B.J. Anderson, D.C. Hamilton, Electromagnetic ion cyclotron waves stimulated by modest magnetospheric compressions. J. Geophys. Res. 98, 11 (1993). doi:10.1029/93JA00605

P.C. Anderson, W.B. Hanson, R.A. Heelis, J.D. Craven, D.N. Baker, L.A. Frank, A proposed production model of rapid subauroral ion drifts and their relationship to substorm evolution. J. Geophys. Res. 98, 6069-6078 (1993). doi:10.1029/92JA01975

V.A. Andreeva, N.A. Tsyganenko, Reconstructing the magnetosphere from data using radial basis functions. J. Geophys. Res. Space Phys. 121, 2249-2263 (2016). doi:10.1002/2015JA022242

E.E. Antonova, N.Yu. Ganushkina, Azimuthal hot plasma pressure gradients and dawn-dusk electric field formation. J. Atmos. Terr. Phys. 59, 1343-1354 (1997)

D.N. Baker, Satellite anomalies due to space storms, in Space Storms and Space Weather Hazards, ed. by I.A. Daglis (2001), p. 285

R. Bala, P. Reiff, Improvements in short-term forecasting of geomagnetic activity. Space Weather 10, S06001 (2012). doi:10.1029/2012SW000779

M.A. Balikhin, R.J. Boynton, S.N. Walker, J.E. Borovsky, S.A. Billings, H.L. Wei, Using the NARMAX approach to model the evolution of energetic electrons fluxes at geostationary orbit. Geophys. Res. Lett. 38(18), L18105 (2011)

C. Barbosa, L. Alves, R. Caraballo, G.A. Hartmann, A.R.R. Papa, R.J. Pirjola, Analysis of geomagnetically induced currents at a low-latitude region over the solar cycles 23 and 24: Comparison between measurements and calculations. J. Space Weather Space Clim. 5, A35 (2015). doi:10.1051/swsc/2015036

Su. Basu, S. Basu, J.J. Makela, E. MacKenzie, P. Doherty, J.W. Wright, F. Rich, M.J. Keskinen, R.E. Sheehan, A.J. Coster, Large magnetic storm-induced nighttime ionospheric flows at midlatitudes and their impacts on GPS-based navigation systems. J. Geophys. Res. 113, A00A06 (2008). doi:10.1029/2008JA013076

M.J. Beharrell, F. Honary, Decoding solar wind-magnetosphere coupling. Space Weather 14, 724-741 (2016). doi:10.1002/2016SW001467

T.J. Birmingham, Birkeland currents in an anisotropic, magnetostatic plasma. J. Geophys. Res. 97(A4), 39073917 (1992). doi:10.1029/91JA03029

O.M. Boaghe, M.A. Balikhin, S.A. Billings, H. Alleyne, Identification of nonlinear processes in the magnetospheric dynamics and forecasting of Dst index. J. Geophys. Res. 106, 30047-30066 (2001). doi:10. 1029/2000JA900162

J.E. Borovsky, M.F. Thomsen, R.C. Elphic, T.E. Cayton, D.J. McComas, The transport of plasma sheet material from the distant tail to geosynchronous orbit. J. Geophys. Res. 103, 20297-20331 (1998)

D.H. Boteler, Space weather effects on power systems, in Space Weather, ed. by D. Song, H.J. Singer, G.L. Siscoe. AGU Geophysical Monograph, vol. 125 (2001), pp. 347-352

S. Bourdarie, V.K. Jordanova, M. Liemohn, T.P. O'Brien, Modeling the energetic particles of the inner magnetosphere, in Waves, Particles, and Storms in Geospace: A Complex Interplay, ed. by G. Balasis, I.A. Daglis, I.R. Mann (Oxford Scholarship, London, 2016). doi:10.1093/acprof:oso/9780198705246. 003.0006

C. Boyle, P. Reiff, M. Hairston, Empirical polar cap potentials. J. Geophys. Res. 102(A1), 111-125 (1997)

R.J. Boynton, M.A. Balikhin, S.A. Billings, A.S. Sharma, O.A. Amariutei, Data derived NARMAX Dst model. Ann. Geophys. 29, 965-971 (2011a)

R.J. Boynton, M.A. Balikhin, S.A. Billings, H.L. Wei, N. Ganushkina, Using the NARMAX OLS-ERR algorithm to obtain the most influential coupling functions that affect the evolution of the magnetosphere. J. Geophys. Res. 116(A5), A05218 (2011b)

R.J. Boynton, M.A. Balikhin, S.A. Billings, Online NARMAX model for electron fluxes at GEO. Ann. Geophys. 33(3), 405-411 (2015)

R.J. Boynton, M.A. Balikhin, D.G. Sibeck, S.N. Walker, S.A. Billings, N. Ganushkina, Electron flux models for different energies at geostationary orbit. Space Weather 14, 846-860 (2016). doi:10.1002/ 2016SW001506

N.M. Brice, Bulk motion of the magnetosphere. J. Geophys. Res. 72, 5193 (1967)

J.L. Burch, D.G. Mitchell, B.R. Sandel, P.C. Brandt, M. Wuest, Global dynamics of the plasmasphere and ring current during magnetic storms. Geophys. Res. Lett. 28, 1159-1162 (2001). doi:10.1029/ 2000GL012413

W.J. Burke, N.C. Maynard, M.P. Hagan, R.A. Wolf, G.R. Wilson, L.C. Gentile, M.S. Gussenhoven, C.Y. Huang, T.W. Garner, F.J. Rich, Electrodynamics of the inner magnetosphere observed in the dusk sector by CRESS and DMSP during the magnetic storm of June 4-6, 1991. J. Geophys. Res. 103, 29399-29418 (1998)

R.K. Burton, R.L. McPherron, C.T. Russell, An empirical relationship between interplanetary conditions and Dst. J. Geophys. Res. 80, 4204-4214 (1975)

G.S. Bust, G. Crowley, T.W. Garner, T.L. Gaussiran, R.W. Meggs, C.N. Mitchell, P.S.J. Spencer, P. Yin, B. Zapfe, Four-dimensional GPS imaging of space weather storms. Space Weather 5, 2 (2007) 
S. Califf, X. Li, R.A. Wolf, H. Zhao, A.N. Jaynes, F.D. Wilder, D.M. Malaspina, R. Redmon, Large-amplitude electric fields in the inner magnetosphere: Van Allen Probes observations of subauroral polarization streams. J. Geophys. Res. 121, 5294-5306 (2016). doi:10.1002/2015JA022252

R.L. Carovillano, G.L. Siscoe, Energy and momentum theorems in magnetospheric processes. Rev. Geophys. Space Phys. 11, 289-353 (1973)

D.L. Carpenter, Whistler evidence of dynamic behavior of the duskside bulge in the plasmasphere. J. Geophys. Res. 75, 3837 (1970)

S. Chapman, V.C.A. Ferraro, A new theory of magnetic storms. Terr. Magn. 36, 77-78 (1931)

S. Chapman, V.C.A. Ferraro, The geomagnetic ring-current: Its radial stability. Terr. Magn. 46, 1-6 (1941)

A.J. Chen, R.A. Wolf, Effects on the plasmasphere of a time-varying convection electric field. Planet. Space Sci. 20, 483 (1972)

M.W. Chen, L.R. Lyons, M. Schulz, Simulations of phase space distributions of storm time proton ring current. J. Geophys. Res. 99, 5745 (1994)

M.W. Chen, M. Schulz, S. Liu et al., Simulated stormtime ring-current magnetic field produced by ions and electrons, in Inner Magnetosphere Interactions: New Perspective from Imaging, ed. by J. Burch, M. Schulz, H. Spence. Geophys. Monogr. Ser., vol. 159 (Am. Geophys. Union, Washington, 2005), pp. 237-250. doi:10.1029/GM159

M.W. Chen, S. Liu, M. Schulz, J.L. Roeder, L.R. Lyons, Magnetically self-consistent ring current simulations during the 19 October 1998 storm. J. Geophys. Res. 111, A11S15 (2006). doi:10.1029/2006JA011620

Y. Chen, G.D. Reeves, R.H.W. Friedel, The energization of relativistic electrons in the outer Van Allen radiation belt. Nat. Phys. 3, 614-617 (2007). doi:10.1038/nphys655

M.W. Chen, C.L. Lemon, K. Orlova, Y. Shprits, J. Hecht, R.L. Walterscheid, Comparison of simulated and observed trapped and precipitating electron fluxes during a magnetic storm. Geophys. Res. Lett. 42, 8302-8311 (2015). doi:10.1002/2015GL065737

M.V. Codrescu, C. Negrea, M. Fedrizzi, T.J. Fuller-Rowell, A. Dobin, N. Jakowsky, H. Khalsa, T. Matsuo, N. Maruyama, A real-time run of the Coupled Thermosphere Ionosphere Plasmasphere Electrodynamics (CTIPe) model. Space Weather 10, S02001 (2012). doi:10.1029/2011SW000736

A. Coster, S. Skone, Monitoring storm-enhanced density using IGS reference station data. J. Geod. 83(3-4), 345 (2009)

I.A. Daglis, The storm-time ring current. Space Sci. Rev. 98, 343-363 (2001)

I.A. Daglis, Ring current dynamics. Space Sci. Rev. 124, 183-202 (2006). doi:10.1007/s11214-006-9104-Z

I.A. Daglis, J.U. Kozyra, Outstanding issues of ring current dynamics. J. Atmos. Sol.-Terr. Phys. 64, 253-264 (2002)

M. David, J.J. Sojka, R.W. Schunk, M.W. Liemohn, A.J. Coster, Dayside mid-latitude ionospheric response to storm-time electric fields. J. Geophys. Res. 116, A12302 (2011). doi:10.1029/2011JA016988

V.A. Davis, M.J. Mandell, M.F. Thomsen, Representation of the measured geosynchronous plasma environment in spacecraft charging calculations. J. Geophys. Res. 113, A10204 (2008). doi:10.1029/ 2008JA013116

P. De Michelis, I.A. Daglis, G. Consolini, Average terrestrial ring current derived from AMPTE/CCE-CHEM measurements. J. Geophys. Res. 102, 14103-14111 (1997)

D.L. De Zeeuw, T.I. Gombosi, C.P.T. Groth, K.G. Powell, Q.F. Stout, An adaptive MHD method for global space weather simulations. IEEE Trans. Plasma Sci. 28(6), 1956-1965 (2000). doi:10.1109/27.902224

V.I. Degtyarev, G.V. Popov, S.S. Sheshukov, Modelling the dynamics of fluxes of electrons with energies 30-300 keV in geostationary orbit. Geomagn. Aeron. 30, 866-868 (1990)

M.H. Denton, M.F. Thomsen, V.K. Jordanova, M.G. Henderson, J.E. Borovsky, J.S. Denton, D. Pitchford, D.P. Hartley, An empirical model of electron and ion fluxes derived from observations at geosynchronous orbit. Space Weather 13, 233-249 (2015). doi:10.1002/2015SW001168

M.H. Denton, M.G. Henderson, V.K. Jordanova, M.F. Thomsen, J.E. Borovsky, J. Woodroffe, D.P. Hartley, D. Pitchford, An improved empirical model of electron and ion fluxes at geosynchronous orbit based on upstream solar wind conditions. Space Weather 14, 511-523 (2016). doi:10.1002/2016SW001409

M.H. Denton, G.D. Reeves, B.A. Larsen, R.H.W. Friedel, M.F. Thomsen, P.A. Fernandes, R.M. Skoug, H.O. Funsten, L.K. Sarno-Smith, On the origin of low-energy electrons in the inner magnetosphere: Fluxes and pitch-angle distributions. J. Geophys. Res. Space Phys. 122, 1789-1802 (2017). doi:10.1002/ 2016JA023648

A.J. Dessler, E.N. Parker, Hydromagnetic theory of geomagnetic storms. J. Geophys. Res. 64, 2239 (1959)

S.A. Dolenko, I.N. Myagkova, V.R. Shiroky, I.G. Persiantsev, Objective discrimination of geomagnetic disturbances and prediction of Dst index by artificial neural networks, in Proceedings of the 10th Intl. Conf. Problems of Geocosmos (2014), pp. 270-275

M.W. Dunlop, S. Haaland, P.C. Escoubet, X.-C. Dong, Commentary on accessing 3-D currents in space: Experiences from cluster. J. Geophys. Res. 121, 7881-7886 (2016). doi:10.1002/2016JA022668 
Y. Ebihara, Chapter 9: Ring current, in Space Weather Fundamentals, ed. by G.V. Khazanov (CRC Press, Boca Raton, 2016)

Y. Ebihara, M. Ejiri, Simulation study on fundamental properties of the storm-time ring current. J. Geophys. Res. 105, 15843 (2000)

Y. Ebihara, M. Ejiri, Numerical simulation of the ring current: Review. Space Sci. Rev. 105, 377-452 (2003). doi:10.1023/A:1023905607888

Y. Ebihara, Y. Miyoshi, Dynamic inner magnetosphere: A tutorial and recent advances, in The Dynamic Magnetosphere, ed. by W. Liu, M. Fujimoto (Springer, Berlin, 2011). doi:10.1007/978-94-007-0501-2

Y. Ebihara, M.-C. Fok, R.A. Wolf, T.J. Immel, T.E. Moore, Influence of ionospheric conductivity on the ring current. J. Geophys. Res. 109, A08205 (2004). doi:10.1029/2003JA010351

A. Egeland, W.J. Burke, The ring current: A short biography. Hist. Geo- Space Sci. 3, 131-142 (2012)

S.R. Elkington, M. Wiltberger, A.A. Chan, D.N. Baker, Physical models of the geospace radiation environment. J. Atmos. Sol.-Terr. Phys. 66, 1371-1387 (2004)

P.J. Erickson, F. Beroz, M.Z. Miskin, Statistical characterization of the American sector subauroral polarization stream using incoherent scatter radar. J. Geophys. Res. 116, A00J21 (2011). doi:10.1029/ 2010JA015738

J.F. Fennell, H.C. Koons, J.L. Roeder, J.B. Blake, Spacecraft charging: Observations and relationship to satellite anomalies, in Proceedings of 7th Spacecraft Charging Technology Conference, vol. 476 (European Space Agency, Noordwijk, Netherlands, 2001), pp. 279-285

F.R. Fenrich, J.G. Luhmann, Geomagnetic response to magnetic clouds of different polarity. Geophys. Res. Lett. 25, 2999-3002 (1998)

M.-C. Fok, T.E. Moore, Ring current modeling in a realistic magnetic field configuration. Geophys. Res. Lett. 24, 1775-1778 (1997)

M.-C. Fok, T.E. Moore, D.C. Delcourt, Modeling of inner plasma sheet and ring current during substorms. J. Geophys. Res. 104, 14557-14569 (1999)

M.-C. Fok, T.E. Moore, W.N. Spjeldvik, Rapid enhancement of radiation belt electron fluxes due to substorm dipolarization of the geomagnetic field. J. Geophys. Res. 106(A3), 3873-3882 (2001a). doi:10.1029/ 2000JA000150

M.-C. Fok, R.A. Wolf, R.W. Spiro, T.E. Moore, Comprehensive computational model of the Earth's ring current. J. Geophys. Res. 106, 8417-8424 (2001b)

M.-C. Fok, A. Glocer, Q. Zheng, R.B. Horne, N.P. Meredith, J.M. Albert, T. Nagai, Recent developments in the radiation belt environment model. J. Atmos. Sol.-Terr. Phys. 73, 1435-1443 (2011)

M.-C. Fok, N.Y. Buzulukova, S.-H. Chen, A. Glocer, T. Nagai, P. Valek, J.D. Perez, The comprehensive inner magnetosphere-ionosphere model. J. Geophys. Res. Space Phys. 119, 7522-7540 (2014). doi:10.1002/ 2014JA020239

J.C. Foster, W.J. Burke, SAPS: A new categorization of subauroral electric fields. Eos Trans. AGU 83(36), 393 (2002)

J.C. Foster, H.B. Vo, Average characteristics and activity dependence of the subauroral polarization stream. J. Geophys. Res. 107(A12), 1475 (2002). doi:10.1029/2002JA009409

J.C. Foster, P.J. Erickson, A.J. Coster, J. Goldstein, F.J. Rich, Ionospheric signatures of plasmaspheric tails. Geophys. Res. Lett. 29, 1623 (2002). doi:10.1029/2002GL015067

L.A. Frank, Several observations of low-energy protons and electrons in the Earth's magnetosphere with OGO 3. J. Geophys. Res. 72, 1905-1916 (1967)

L.A. Frank, Direct detection of asymmetric increases of extraterrestrial 'Ring Current' proton intensities in the outer radiation zone. J. Geophys. Res. 75, 1263-1268 (1970)

R.H.W. Friedel, A. Korth, Review of CRRES ring current observations. Adv. Space Res. 20, 311-320 (1997). doi:10.1016/S0273-1177(97)00673-X

R.H.W. Friedel, H. Korth, M.G. Henderson, M.E. Thomsen, J.D. Scudder, Plasma sheet access to the inner magnetosphere. J. Geophys. Res. 106, 5845-5858 (2001)

E. Friedrich, G. Rostoker, M.G. Connors, R.L. McPherron, Influence of the substorm current wedge on the Dst index. J. Geophys. Res. 104(A3), 4567-4575 (1999). doi:10.1029/1998JA900096

C. Gabrielse, V. Angelopoulos, A. Runov, D.L. Turner, The effects of transient, localized electric fields on equatorial electron acceleration and transport toward the inner magnetosphere. J. Geophys. Res. 117, A10213 (2012). doi:10.1029/2012JA017873

C. Gabrielse, V. Angelopoulos, A. Runov, D.L. Turner, Statistical characteristics of particle injections throughout the equatorial magnetotail. J. Geophys. Res. Space Phys. 119, 2512-2535 (2014). doi:10. 1002/2013JA019638

C. Gabrielse, C. Harris, V. Angelopoulos, A. Artemyev, A. Runov, The role of localized inductive electric fields in electron injections around dipolarizing flux bundles. J. Geophys. Res. Space Phys. 121, 95609585 (2016). doi:10.1002/2016JA023061 
D.L. Gallagher, M.L. Adrian, M.W. Liemohn, The origin and evolution of deep plasmaspheric notches. J. Geophys. Res. 110, A09201 (2005). doi:10.1029/2004JA010906

Y. Galperin, V.N. Ponomarev, A.G. Zosimova, Plasma convection in the polar ionosphere. Ann. Geophys. 30, 1-7 (1974)

N.Yu. Ganushkina, Drivers of the inner magnetosphere, in The Inner Magnetosphere: Physics and Modeling, ed. by T.I. Pulkkinen, N.A. Tsyganenko, R.H.W. Friedel. Geophysical Monograph Series, vol. 155 (Am. Geophys. Union, Washington, 2005), pp. 135-145. doi:10.1029/155GM16

N.Y. Ganushkina, T.I. Pulkkinen, M.V. Kubyshkina, H.J. Singer, C.T. Russell, Long-term evolution of magnetospheric current systems during storms. Ann. Geophys. 22, 1317-1334 (2004)

N.Y. Ganushkina, M. Liemohn, M. Kubyshkina, R. Ilie, H. Singer, Distortions of the magnetic field by stormtime current systems in Earth's magnetosphere. Ann. Geophys. 28, 123-140 (2010)

N.Yu. Ganushkina, M.W. Liemohn, T.I. Pulkkinen, Storm-time ring current: Model-dependent results. Ann. Geophys. 30, 177-202 (2012)

N.Y. Ganushkina, O. Amariutei, Y.Y. Shpritz, M. Liemohn, Transport of the plasma sheet electrons to the geostationary distances. J. Geophys. Res. 118, 82-98 (2013). doi:10.1029/2012JA017923

N.Y. Ganushkina, M. Liemohn, O. Amariutei, D. Pitchford, Low energy electrons (5-50 keV) in the inner magnetosphere. J. Geophys. Res. 119, 246-259 (2014). doi:10.1002/2013JA019304

N.Y. Ganushkina, O.A. Amariutei, D. Welling, D. Heynderickx, Nowcast model for low-energy electrons in the inner magnetosphere. Space Weather 13, 16-34 (2015a). doi:10.1002/2014SW001098

N.Y. Ganushkina, M.W. Liemohn, S. Dubyagin et al., Defining and resolving current systems in geospace. Ann. Geophys. 33, 1369-1402 (2015b). doi:10.5194/angeo-33-1369-2015

T.W. Garner, R.A. Wolf, R.W. Spiro, W.J. Burke, B.G. Fejer, S. Sazykin, J.L. Roeder, M.R. Hairston, Magnetospheric electric fields and plasma sheet injection to low L-shells during the 4-5 June 1991 magnetic storm: Comparison between the rice convection model and observations. J. Geophys. Res. 109, A02214 (2004). doi:10.1029/2003JA010208

H.B. Garrett, The charging of spacecraft surfaces. Rev. Geophys. 19(4), 577 (1981). doi:10.1029/ RG019i004p00577

M. Gkioulidou, A.Y. Ukhorskiy, D.G. Mitchell, L.J. Lanzerotti, Storm time dynamics of ring current protons: Implications for the long-term energy budget in the inner magnetosphere. Geophys. Res. Lett. 43, 47364744 (2016). doi:10.1002/2016GL068013

A. Glocer et al., Community-wide validation of geospace model local K-index predictions to support model transition to operations. Space Weather 14, 469-480 (2016). doi:10.1002/2016SW001387

J. Goldstein, B.R. Sandel, M.R. Hairston, P.H. Reiff, Control of plasmaspheric dynamics by both convection and sub-auroral polarization stream. Geophys. Res. Lett. 30(24), 2243 (2003). doi:10.1029/ 2003GL018390

J. Goldstein, B.R. Sandel, M.F. Thomsen, M. Spasojevic, P.H. Reiff, Simultaneous remote sensing and in situ observations of plasmaspheric drainage plumes. J. Geophys. Res. Space Phys. 109, A03202 (2004). doi:10.1029/2003JA010281

C.A. Gonzales, M.C. Kelley, L.A. Carpenter, R.H. Holzworth, Evidence for a magnetospheric effect on midlatitude electric fields. J. Geophys. Res. 83, 4397-4399 (1978)

W.D. Gonzalez, J.A. Joselyn, Y. Kamide, H.W. Kroehl, G. Rostoker, B.T. Tsurutani, V.M. Vasyliunas, What is a geomagnetic storm? J. Geophys. Res. 99, 5771-5792 (1994)

O.S. Grafodatskiy, V.I. Degtyarev, A.G. Kozlov, V.I. Lazarev, O.I. Platonov, G.V. Popov, M.V. Teltsov, Relationship between characteristics of low-energy electrons and geomagnetic disturbance in geostationary orbit. Geomagn. Aeron. 27, 494-496 (1987)

M. Grande, C.H. Perry, A. Hall, J. Fennell, B. Wilken, Survey of ring current composition during magnetic storms. Adv. Space Res. 20, 321-326 (1997). doi:10.1016/S0273-1177(97)00675-3

J.M. Grebowsky, Model study of plasmapause motion. J. Geophys. Res. 75, 4329 (1970)

J.C. Green, Using electron phase space density signatures to identify the electromagnetic waves responsible for accelerating relativistic electrons in Earth's magnetosphere, in Magnetospheric ULF Waves: Synthesis and New Directions, ed. by K. Takahashi, P.J. Chi, R.E. Denton, R.L. Lysak. Washington DC American Geophysical Union Geophysical Monograph Series, vol. 169 (2006), p. 225

M.E. Greenspan, D.C. Hamilton, A test of the Dessler-Parker-Sckopke relation during magnetic storms. J. Geophys. Res. 105, 5419-5430 (2000)

R. Gubby, E. Evans, Space environment effects and satellite design. J. Atmos. Sol.-Terr. Phys. 64(16), 17231733 (2002)

R.A. Heelis, W.R. Coley, Variations in the low- and middle-latitude topside ion concentration observed by DMSP during superstorm events. J. Geophys. Res. 112, A08310 (2007). doi:10.1029/2007JA012326

M. Heinemann, Representations of currents and magnetic fields in anisotropic magnetohydrostatic plasma. J. Geophys. Res. 95, 7789-7797 (1990) 
M. Heinemann, D.H. Pontius, Representation of currents and magnetic fields in anisotropic magnetohydrostatic plasma. 2. General theory and examples. J. Geophys. Res. 96, 17609-17626 (1991)

R.A. Helliwell, A theory of discrete VLF emissions from the magnetosphere. J. Geophys. Res. 72, 4773-4790 (1967). doi:10.1029/JZ072i019p04773

R.B. Horne, R.M. Thorne, Potential waves for relativistic electron scattering and stochastic acceleration during magnetic storms. Geophys. Res. Lett. 25, 3011-3014 (1998). doi:10.1029/98GL01002

R.B. Horne, R.M. Thorne, Y.Y. Shprits, N.P. Meredith, S.A. Glauert, A.J. Smith, S.G. Kanekal, D.N. Baker, M.J. Engebretson, J.L. Posch, M. Spasojevic, U.S. Inan, J.S. Pickett, P.M.E. Decreau, Wave acceleration of electrons in the Van Allen radiation belts. Nature 437, 227-230 (2005). doi:10.1038/nature03939

I. Horvath, B.C. Lovell, Storm-enhanced plasma density features, daytime polar cap plasma enhancements, and their underlying plasma flows investigated during superstorms. J. Geophys. Res. 114, A11304 (2009). doi:10.1029/2009JA014465

I. Horvath, B.C. Lovell, Investigating storm-enhanced density and polar tongue of ionization development during the 22 October 1999 great storm. J. Geophys. Res. Space Phys. 120, 1428-1444 (2015). doi:10. 1002/2014JA020598

C.-S. Huang, J.C. Foster, Correlation of the subauroral polarization streams (SAPS) with the Dst index during severe magnetic storms. J. Geophys. Res. 112, A11302 (2007). doi:10.1029/2007JA012584

M.K. Hudson, V.A. Marchenko, I. Roth, M. Temerin, J.B. Blake, M.S. Gussenhoven, Radiation belt formation during storm sudden commencements and loss during main phase. Adv. Space Res. 21(4), 597-607 (1998)

J.C. Ingraham, T.E. Cayton, R.D. Belian, R.A. Christensen, R.H.W. Friedel, M.M. Meier, G.D. Reeves, M. Tuszewski, Substorm injection of relativistic electrons to geosynchronous orbit during the great magnetic storm of March 24, 1991. J. Geophys. Res. 106, 25759-25776 (2001)

T. Iyemori, Storm-time magnetospheric currents inferred from mid-latitude geomagnetic field variations. J. Geomagn. Geoelectr. 42, 1249-1265 (1990)

R.K. Jaggi, R.A. Wolf, Self-consistent calculation of the motion of a sheet of ions in the magnetosphere. J. Geophys. Res. 78, 2852 (1973). doi:10.1029/JA078i016p02852

E.-Y. Ji, Y.-J. Moon, N. Gopalswamy, D.-H. Lee, Comparison of Dst forecast models for intense geomagnetic storms. J. Geophys. Res. 117, A03209 (2012). doi:10.1029/2011JA016872

V.K. Jordanova, New insights on geomagnetic storms from model simulations using multi-spacecraft data. Space Sci. Rev. 107, 157-165 (2003)

V.K. Jordanova, Y.S. Miyoshi, Relativistic model of ring current and radiation belt ions and electrons: Initial results. Geophys. Res. Lett. 32, L14104 (2005). doi:10.1029/2005GL023020

V.K. Jordanova, L.M. Kistler, J.U. Kozyra, G.V. Khazanov, A.F. Nagy, Collisional losses of ring current ions. J. Geophys. Res. 101, 111 (1996)

V.K. Jordanova, L.M. Kistler, C.J. Farrugia, R.B. Torbert, Effects of inner magnetospheric convection on ring current dynamics: March 10-12, 1998. J. Geophys. Res. 106, 29705-29720 (2001)

V.K. Jordanova, S. Zaharia, D.T. Welling, Comparative study of ring current development using empirical, dipolar, and self-consistent magnetic field simulations. J. Geophys. Res. 115, A00J11 (2010). doi:10. 1029/2010JA015671

V.K. Jordanova, D.T. Welling, S.G. Zaharia, L. Chen, R.M. Thorne, Modeling ring current ion and electron dynamics and plasma instabilities during a high-speed stream driven storm. J. Geophys. Res. 117, A00L08 (2012). doi:10.1029/2011JA017433

V.K. Jordanova, Y. Yu, J.T. Niehof, R.M. Skoug, G.D. Reeves, C.A. Kletzing, J.F. Fennell, H.E. Spence, Simulations of inner magnetosphere dynamics with an expanded RAM-SCB model and comparisons with Van Allen Probes observations. Geophys. Res. Lett. 41, 2687-2694 (2014). doi:10.1002/ 2014GL059533

V.K. Jordanova, W. Tu, Y. Chen, S.K. Morley, A.-D. Panaitescu, G.D. Reeves, C.A. Kletzing, RAM-SCB simulations of electron transport and plasma wave scattering during the October 2012 "double-dip" storm. J. Geophys. Res. Space Phys. 121, 8712-8727 (2016). doi:10.1002/2016JA022470

V.V. Kalegaev, N.Y. Ganushkina, T.I. Pulkkinen, M.V. Kubyshkina, H.J. Singer, C.T. Russell, Relation between the ring current and the tail current during magnetic storms. Ann. Geophys. 23, 523-533 (2005)

Y. Kamide, Association of DP and DR fields with the interplanetary magnetic field variation. J. Geophys. Res. 79, 49-55 (1974). doi:10.1029/JA079i001p00049

Y. Kamide, N. Fukushima, Analysis of magnetic storms with DR indices for equatorial ring-current field. Radio Sci. 6, 277-278 (1971). doi:10.1029/RS006i002p00277

J.G. Kappenman, Storm sudden commencement events and the associated geomagnetically induced current risks to ground-based systems at low-latitude and midlatitude locations. Space Weather 1, 1016 (2003). doi:10.1029/2003SW000009

J.G. Kappenman, L.J. Zanetti, W.A. Radasky, Geomagnetic storms can threaten electric power grid. Earth Space 9(7), 9-11 (1997) 
T. Karlsson, G.T. Marklund, L.G. Blomberg, A. Mälkki, Subauroral electric fields observed by the Freja satellite: A statistical study. J. Geophys. Res. 103, 4327-4341 (1998). doi:10.1029/97JA00333

R.M. Katus, M.W. Liemohn, E.L. Ionides, R. Ilie, D. Welling, L.K. Sarno-Smith, Statistical analysis of the geomagnetic response to different solar wind drivers and the dependence on storm intensity. J. Geophys. Res. Space Phys. 120, 310-327 (2015). doi:10.1002/2014JA020712

M.C. Kelley, M.N. Vlasov, J.C. Foster, A.J. Coster, A quantitative explanation for the phenomenon known as storm-enhanced density. Geophys. Res. Lett. 31, L19809 (2004). doi:10.1029/2004GL020875

C.F. Kennel, H.E. Petschek, Limit on stably trapped particle fluxes. J. Geophys. Res. 71, 1 (1966)

C.F. Kennel, R.M. Thorne, Unstable growth of unducted whistlers propagating at an angle to the geomagnetic field. J. Geophys. Res. 72(3), 871-878 (1967). doi:10.1029/JZ072i003p00871

G.V. Khazanov, T.S. Newman, M.W. Liemohn, M.-C. Fok, R.W. Spiro, Self-consistent magnetosphereionosphere coupling: Theoretical studies. J. Geophys. Res. 107(A3), 1122 (2003). doi:10.1029/ 2002JA009624

G.V. Khazanov, M.W. Liemohn, T.S. Newman, M.-C. Fok, A.J. Ridley, Magnetospheric convection electric field dynamics and stormtime particle energization: Case study of the magnetic storm of 4 May 1998. Ann. Geophys. 22, 497 (2004)

H.-J. Kim, A.A. Chan, Fully adiabatic changes in storm time relativistic electron fluxes. J. Geophys. Res. 102, 22107 (1997)

J.S. Kim, D.A. Graham, C.S. Wang, Inductive electric fields in the ionosphere-magnetosphere system. Rev. Geophys. Space Phys. 17, 2049-2056 (1979)

L.M. Kistler et al., The source of $\mathrm{O}^{+}$in the storm time ring current. J. Geophys. Res. Space Phys. 121, 5333-5349 (2016). doi:10.1002/2015JA022204

A.J. Klimas, D. Vassiliadis, D.N. Baker, Dst index prediction using data-derived analogues of the magnetospheric dynamics. J. Geophys. Res. 103, 20435-20447 (1998)

H.C. Koons, J.E. Mazur, R.S. Selesnick, J.B. Blake, J.F. Fennell, J.L. Roeder, P.C. Anderson, The impact of the space environment on space systems. Aerospace Rep. TR-99 (1670)-1, Aerospace Corp., El Segundo, CA (1999)

H. Korth, M.F. Thomsen, J.E. Borovsky, D.J. McComas, Plasma sheet access to geosynchronous orbit. J. Geophys. Res. 104, 25047-25061 (1999)

T.V. Kozelova, L.L. Lazutin, B.V. Kozelov, N. Meredith, M.A. Danielides, Alternating bursts of low energy ions and electrons near the substorm onset. Ann. Geophys. 24, 1957-1968 (2006)

J.U. Kozyra, M.W. Liemohn, Ring current energy input and decay. Space Sci. Rev. 109, 105-131 (2003)

J.U. Kozyra, C.E. Rasmussen, R.H. Miller, L.R. Lyons, Interaction of ring current and radiation belt protons with ducted plasmaspheric hiss. 1: Diffusion coefficients and timescales. J. Geophys. Res. 99, 40694084 (1994). doi:10.1029/93JA01532

J.U. Kozyra, A.F. Nagy, D.W. Slater, High-altitude energy source(s) for stable auroral red arcs. Rev. Geophys. 35(2), 155-190 (1997). doi:10.1029/96RG03194

E.A. Kronberg, M. Ashour-Abdalla, I. Dandouras et al., Circulation of heavy ions and their dynamical effects in the magnetosphere: Recent observations and models. Space Sci. Rev. 184, 173-235 (2014). doi:10.1007/s11214-014-0104-0

S. Kurita, Y. Miyoshi, F. Tsuchiya, Y. Nishimura, T. Hori, Y. Miyashita, T. Takada, A. Morioka, V. Angelopoulos, J.P. McFadden, H.U. Auster, J.M. Albert, V. Jordanova, H. Misawa, Transport and loss of the inner plasma sheet electrons: THEMIS observations. J. Geophys. Res. 116, A03201 (2011). doi:10. 1029/2010JA015975

L.J. Lanzerotti, K. LaFleur, C.G. Maclennan, D.W. Maurer, Geosynchronous spacecraft charging in January 1997. Geophys. Res. Lett. 25(15), 2967-2970 (1998)

C. Lemon, R. Wolf, T.W. Hill, S. Sazykin, Magnetic storm ring current injection modeled with the rice convection model and a self-consistent magnetic field. Geophys. Res. Lett. 31, L21801 (2004). doi:10. 1029/2004GL020914

I.J. Leontaritis, S.A. Billings, Input-output parametric models for non-linear systems part i: Deterministic non-linear systems. Int. J. Control 41(2), 303-328 (1985a)

I.J. Leontaritis, S.A. Billings, Input-output parametric models for non-linear systems part ii: Stochastic nonlinear systems. Int. J. Control 41(2), 329-344 (1985b)

X. Li, D.N. Baker, M. Temerin et al., Simulation of dispersionless injections and drift echoes of energetic electrons associated with substorms. Geophys. Res. Lett. 25, 3763-3766 (1998)

X. Li, T.E. Sarris, D.N. Baker, W.K. Peterson, H.J. Singer, Simulation of energetic particle injections associated with a substorm on August 27, 2001. Geophys. Res. Lett. 30, 1004 (2003). doi:10.1029/ 2002GL015967

W. Li, R.M. Thorne, N.P. Meredith, R.B. Horne, J. Bortnik, Y.Y. Shprits, B. Ni, Evaluation of whistler-mode chorus amplification during an injection event observed on CRRES. J. Geophys. Res. 113, A09210 (2008). doi:10.1029/2008JA013129 
W. Li, R. Thorne, J. Bortnik, R. McPherron, Y. Nishimura, V. Angelopoulos, I.G. Richardson, Evolution of chorus waves and their source electrons during storms driven by corotating interaction regions. J. Geophys. Res. 117, A08209 (2012). doi:10.1029/2012JA017797

M.W. Liemohn, Yet another caveat to using the Dessler-Parker-Sckopke relation. J. Geophys. Res. 108(A6), 1251 (2003). doi:10.1029/2003JA009839

M.W. Liemohn, Introduction to the special section on "Results of the national science foundation geospace environment modeling inner magnetosphere/storms assessment challenge”. J. Geophys. Res. 111, A11S01 (2006). doi:10.1029/2006JA011970

M.W. Liemohn, J.U. Kozyra, C.R. Clauer, A.J. Ridley, Computational analysis of the near-Earth magnetospheric current system. J. Geophys. Res. 106, 29531 (2001a)

M.W. Liemohn, J.U. Kozyra, M.F. Thomsen et al., Dominant role of the asymmetric ring current in producing the stormtime Dst. J. Geophys. Res. 106, 10883-10904 (2001b)

M.W. Liemohn, A.J. Ridley, D.L. Gallagher, D.M. Ober, J.U. Kozyra, Dependence of plasmaspheric morphology on the electric field description during the recovery phase of the April 17, 2002 magnetic storm. J. Geophys. Res. 109(A3), A03209 (2004). doi:10.1029/2003JA010304

M.W. Liemohn, A.J. Ridley, P.C. Brandt, D.L. Gallagher, J.U. Kozyra, D.G. Mitchell, E.C. Roelof, R. DeMajistre, Parametric analysis of nightside conductance effects on inner magnetospheric dynamics for the 17 April 2002 storm. J. Geophys. Res. 110, A12S22 (2005). doi:10.1029/2005JA011109

M.W. Liemohn, N.Y. Ganushkina, R. Ilie, D.T. Welling, Challenges associated with near-Earth nightside current. J. Geophys. Res. Space Phys. 121, 6763-6768 (2016). doi:10.1002/2016JA022948

S. Liu, M.W. Chen, J.L. Roeder, L.R. Lyons, M. Schulz, Relative contribution of electrons to the stormtime total ring current energy content. Geophys. Res. Lett. 32, L03110 (2005). doi:10.1029/2004GL021672

W.L. Liu, X. Li, T. Sarris, C. Cully, R. Ergun, V. Angelopoulos, D. Larson, A. Keiling, K.H. Glassmeier, H.U. Auster, Observation and modeling of the injection observed by THEMIS and LANL satellites during the 23 March 2007 substorm event. J. Geophys. Res. 114, A00C18 (2009). doi:10.1029/2008JA013498

W. Lotko, B.U. Sonnerup, R.L. Lysak, Nonsteady boundary layer flow including ionospheric drag and parallel electric fields. J. Geophys. Res. 92(A8), 8635-8648 (1987). doi:10.1029/JA092iA08p08635

J.Y. Lu, Y.X. Peng, M. Wang, S.J. Gu, M.X. Zhao, Support vector machine combined with distance correlation learning for Dst forecasting during intense geomagnetic storms. Planet. Space Sci. 120, 48-55 (2016)

H. Lühr, C. Xiong, N. Olsen, G. Le, Near-Earth magnetic field effects of large-scale magnetospheric currents. Space Sci. Rev. 206, 521-545 (2017). doi:10.1007/s11214-016-0267-y

A.T.Y. Lui, D.C. Hamilton, Radial profiles of quiet time magnetospheric parameters. J. Geophys. Res. 97, 19325-19332 (1992)

A.T.Y. Lui, R.W. McEntire, S.M. Krimigis, Evolution of the ring current during two geomagnetic storms. J. Geophys. Res. 92, 7459-7470 (1987)

H. Lundstedt, P. Wintoft, Prediction of geomagnetic storms from solar wind data with the use of a neural network. Ann. Geophys. 12, 19-24 (1994)

H. Lundstedt, H. Gleisner, P. Wintoft, Operational forecasts of the geomagnetic Dst index. Geophys. Res. Lett. 106(A6), 1-4 (2001)

H. Lundstedt, H. Gleisner, P. Wintoft, Operational forecasts of the geomagnetic Dst index. Geophys. Res. Lett. 29, 2181 (2002). doi:10.1029/2002GL016151

J.G. Lyon, J.A. Fedder, C.M. Mobarry, The Lyon-Fedder-Mobarry (LFM) global MHD magnetospheric simulation code. J. Atmos. Sol.-Terr. Phys. 66, 1333-1350 (2004). doi:10.1016/j.jastp.2004.03.020

Y.P. Maltsev, Points of controversy in the study of magnetic storms. Space Sci. Rev. 110, 227-277 (2004)

R.A. Marshall, M. Dalzell, C.L. Waters, P. Goldthorpe, E.A. Smith, Geomagnetically induced currents in the New Zealand power network. Space Weather 10, S08003 (2012). doi:10.1029/2012SW000806

J.-C. Matéo-Vélez, A. Sicard-Piet, D. Lazaro, V. Inguimbert, P. Sarrailh, S. Hess, V. Maget, D. Payan, Severe geostationary environments: Numerical estimation of spacecraft surface charging from flight data. J. Spacecr. Rockets 53(2), 304-316 (2016). doi:10.2514/1.A33376

B.H. Mauk, N.J. Fox, S.G. Kanekal, R.L. Kessel, D.G. Sibeck, A. Ukhorskiy, Science objectives and rationale for the radiation belt storm probes mission. Space Sci. Rev. 179, 3-27 (2013). doi:10.1007/s11214012-9908-y

G.D. Mead, D.H. Fairfield, A quantitative magnetospheric model derived from spacecraft magnetometer data. J. Geophys. Res. 80, 523-534 (1975)

A.M. Menz, L.M. Kistler, C.G. Mouikis, H.E. Spence, R.M. Skoug, H.O. Funsten, B.A. Larsen, D.G. Mitchell, M. Gkioulidou, The role of convection in the buildup of the ring current pressure during the 17 March 2013 storm. J. Geophys. Res. Space Phys. 122, 475-492 (2017). doi:10.1002/2016JA023358

N.P. Meredith, R.B. Horne, R.R. Anderson, Substorm dependence of chorus amplitudes: Implications for the acceleration of electrons to relativistic energies. J. Geophys. Res. 106, 13165-13178 (2001) 
N.P. Meredith, R.M. Thorne, R.B. Horne, D. Summers, B.J. Fraser, R.R. Anderson, Statistical analysis of relativistic electron energies for cyclotron resonance with EMIC waves observed on CRRES. J. Geophys. Res. Space Phys. 108, 1250 (2003). doi:10.1029/2002JA009700

E.V. Mishin, W.J. Burke, Stormtime coupling of the ring current, plasmasphere, and topside ionosphere: Electromagnetic and plasma disturbances. J. Geophys. Res. 110, A07209 (2005). doi:10.1029/ 2005JA011021

E. Mishin, E. Sutton, G. Milikh, I. Galkin, C. Roth, M. Förster, F2-region atmospheric gravity waves due to high-power HF heating and subauroral polarization streams. Geophys. Res. Lett. 39, L11101 (2012). doi:10.1029/2012GL052004

D.G. Mitchell, K.C. Hsieh, C.C. Curtis, D.C. Hamilton, H.D. Voss, E.C. Roelof, P. C:son Brandt, Imaging two geomagnetic storms in energetic neutral atoms. Geophys. Res. Lett. 28, 1151-1154 (2001)

M.J. Mithaiwala, W. Horton, Substorm injections produce sufficient electron energization to account for MeV flux enhancements following some storms. J. Geophys. Res. 110, A07224 (2005). doi:10.1029/ 2004JA010511

Y.S. Miyoshi, V.K. Jordanova, A. Morioka, M.F. Thomsen, G.D. Reeves, D.S. Evans, J.C. Green, Observations and modeling of energetic electron dynamics during the October 2001 storm. J. Geophys. Res. 111, A11S02 (2006). doi:10.1029/2005JA011351

T.S. Molinski, Why utilities respect geomagnetically induced currents. J. Atmos. Sol.-Terr. Phys. 64(16), 1765-1778 (2002)

V. Munsami, Determination of the effects of substorms on the storm-time ring current using neural networks. J. Geophys. Res. 105(A12), 27833-27840 (2000). doi:10.1029/2000JA000041

T. Murayama, Coupling function between the solar wind and the Dst index, in Solar Wind-Magnetosphere Coupling, ed. by Y. Kamide, J.A. Slavin (Terra Scientific Publishing Co., Tokyo, 1986), p. 119

C.M. Ngwira, A. Pulkkinen, F.D. Wilder, G. Crowley, Extended study of extreme geoelectric field event scenarios for geomagnetically induced current applications. Space Weather 11, 121-131 (2013). doi:10. 1002/swe. 20021

A. Nishida, Formation of plasmapause, or magnetospheric plasma knee, by the combined action of magnetospheric convection and plasma escape from the tail. J. Geophys. Res. 71, 5669 (1966)

T.P. O'Brien, SEAES-GEO: A spacecraft environmental anomalies expert system for geosynchronous orbit. Space Weather 7, S09003 (2009). doi:10.1029/2009SW000473

T.P. O’Brien, R.L. McPherron, Forecasting the ring current Dst in real time. J. Atmos. Sol.-Terr. Phys. 62, 1295-1299 (2000)

S. Ohtani, M. Nos, G. Rostoker, H. Singer, A.T.Y. Lui, M. Nakamura, Storm-substorm relationship: Contribution of the tail current to Dst. J. Geophys. Res. 106(A10), 21199-21209 (2001). doi:10.1029/ 2000JA000400

G. Pallocchia, E. Amata, G. Consolini, M.F. Marcucci, I. Bertello, Geomagnetic Dst index forecast based on IMF data only. Ann. Geophys. 24, 989-999 (2006)

E.N. Parker, H.A. Stewart, Nonlinear inflation of a magnetic dipole. J. Geophys. Res. 72, 5287 (1967)

B. Pintér, S.D. Thom, R. Balthazor, H. Vo, G.J. Bailey, Modeling subauroral polarization streams equatorward of the plasmapause footprints. J. Geophys. Res. 111, A10306 (2006). doi:10.1029/2005JA011457

R. Pirjola, Geomagnetically induced currents during magnetic storms. IEEE Trans. Plasma Sci. 28(6), 18671873 (2000)

R. Pirjola, Review on the calculation of the surface electric and magnetic fields and geomagnetically induced currents in ground based technological systems. Surv. Geophys. 23, 71-90 (2002)

R. Pirjola, Practical model applicable to investigating the coast effect on the geoelectric field in connection with studies of geomagnetically induced currents. Adv. Appl. Phys. 1(1), 9-28 (2013)

J.L. Posch, M.J. Engebretson, M.T. Murphy, M.H. Denton, M.R. Lessard, R.B. Horne, Probing the relationship between electromagnetic ion cyclotron waves and plasmaspheric plumes near geosynchronous orbit. J. Geophys. Res. Space Phys. 115, A11205 (2010). doi:10.1029/2010JA015446

K. Powell, P. Roe, T. Linde, A solution-adaptive upwind scheme for ideal magnetohydrodynamics. J. Comput. Phys. 154, 284-309 (1999). doi:10.1006/jcph.1999.6299

A. Pulkkinen, L. Rastätter, M. Kuznetsova, M. Hesse, A. Ridley, J. Raeder, H.J. Singer, A. Chulaki, Systematic evaluation of ground and geostationary magnetic field predictions generated by global magnetohydrodynamic models. J. Geophys. Res. 115, A03206 (2010). doi:10.1029/2009JA014537

A. Pulkkinen, M. Kuznetsova, A. Ridley et al., Geospace environment modeling 2008-2009 challenge: Ground magnetic field perturbations. Space Weather 9, S02004 (2011). doi:10.1029/2010SW000600

A. Pulkkinen, E. Bernabeu, J. Eichner, C. Beggan, A.W.P. Thomson, Generation of 100-year geomagnetically induced current scenarios. Space Weather 10, S04003 (2012). doi:10.1029/2011SW000750

A. Pulkkinen, L. Rastätter, M. Kuznetsova et al., Community-wide validation of geospace model ground magnetic field perturbation predictions to support model transition to operations. Space Weather 11, 369-385 (2013). doi:10.1002/swe.20056 
J. Raeder, R.L. McPherron, L.A. Frank, S. Kokubun, G. Lu, T. Mukai, W.R. Paterson, J.B. Sigwarth, H.J. Singer, J.A. Slavin, Global simulation of the geospace environment modeling substorm challenge event. J. Geophys. Res. 106, 381-395 (2001). doi:10.1029/2000JA000605

C.E. Rasmussen, S.M. Guiter, S.G. Thomas, A two-dimensional model of the plasmasphere: Refilling time constants. Planet. Space Sci. 41, 35 (1993)

L. Rastätter, M.M. Kuznetsova, A. Glocer et al., Geospace environment modeling 2008-2009 challenge: Dst index. Space Weather 11, 187-205 (2013). doi:10.1002/swe.20036

L. Rastätter, G. Tóth, M.M. Kuznetsova, A.A. Pulkkinen, CalcDeltaB: An efficient postprocessing tool to calculate ground-level magnetic perturbations from global magnetosphere simulations. Space Weather 12, 553-565 (2014). doi:10.1002/2014SW001083

G.D. Reeves, R.H.W. Friedel, B.A. Larsen, R.M. Skoug, H.O. Funsten, S.G. Claudepierre, J.F. Fennell, D.L. Turner, M.H. Denton, H.E. Spence, J.B. Blake, D.N. Baker, Energy-dependent dynamics of keV to MeV electrons in the inner zone, outer zone, and slot regions. J. Geophys. Res. Space Phys. 121, 397-412 (2016). doi:10.1002/2015JA021569

A.J. Ridley, M.W. Liemohn, A model-derived description of the penetration electric field. J. Geophys. Res. 107(A8), 1151 (2002). doi:10.1029/2001JA00051

A.J. Ridley, D.L. De Zeeuw, T.I. Gombosi, K.G. Powell, Using steady state MHD results to predict the global state of the magnetosphere-ionosphere system. J. Geophys. Res. 106(A12), 30067 (2001). doi:10.1029/ 2000JA002233

A.J. Ridley, T.I. Gombosi, D.L. De Zeeuw, Ionospheric control of the magnetosphere: Conductance. Ann. Geophys. 22, 567 (2004)

C.J. Rodger, M.A. Clilverd, A. Seppala, N.R. Thomson, R.J. Gamble, M. Parrot, J.-A. Sauvaud, T. Ulich, Radiation belt electron precipitation due to geomagnetic storms: Significance to middle atmosphere ozone chemistry. J. Geophys. Res. Space Phys. 115, A11320 (2010). doi:10.1029/2010JA015599

I. Roth, M.K. Hudson, Wave-particle interaction at the plasmasphere-ring current interface. IEEE Trans. Plasma Sci. 20, 829-832 (1992). doi:10.1109/27.199535

T.E. Sarris, X. Li, N. Tsaggas, N. Paschalidis, Modeling energetic particle injections in dynamic pulse fields with varying propagation speeds. J. Geophys. Res. 107, 1033 (2002). doi:10.1029/2001JA900166

S. Sazykin, R.A. Wolf, R.W. Spiro, T.I. Gombosi, D.L. De Zeeuw, M.F. Thomsen, Interchange instability in the inner magnetosphere associated with geosynchronous particle flux decreases. Geophys. Res. Lett. 29(10), 88-1-88-4 (2002). doi:10.1029/2001GL014416

A. Schmidt, Erdmagnetismus, in Enzyklopeadie der Mathem. Wiss., VI (1917), pp. 265-396

M. Schulz, L. Lanzerotti, Particle Diffusion in the Radiation Belts (Springer, New York, 1974)

R.W. Schunk, L. Gardner, L. Scherliess, L. Zhu, Problems associated with uncertain parameters and missing physics for long-term ionosphere-thermosphere forecasting. Radio Sci. 47, RSOL23 (2012). doi:10. 1029/2011RS004911

N. Sckopke, A general relation between the energy of trapped particles and the disturbance field near the Earth. J. Geophys. Res. 71, 3125-3130 (1966)

R. Shi, D. Summers, B. Ni, J.W. Manweiler, D.G. Mitchell, L.J. Lanzerotti, A statistical study of proton pitch angle distributions measured by the radiation belt storm probes ion composition experiment. J. Geophys. Res. Space Phys. 121, 5233-5249 (2016). doi:10.1002/2015JA022140

G.L. Siscoe, W. Lotko, B.U. Sonnerup, A. High-Latitude, Low-latitude boundary layer model of the convection current system. J. Geophys. Res. 96(A3), 3487-3495 (1991). doi:10.1029/90JA02362

P.H. Smith, R.A. Hoffman, Direct observations in the dusk hours of the characteristics of the storm time ring current particles during the beginning of magnetic storms. J. Geophys. Res. 79, 966-971 (1974)

J.J. Sojka, M. David, R.W. Schunk, J.C. Foster, H.B. Vo, A modeling study of the F region response to SAPS. J. Atmos. Sol.-Terr. Phys. 66, 415-423 (2004). doi:10.1016/j.jastp.2003.11.003

M. Spasojević, J. Goldstein, D.L. Carpenter, U.S. Inan, B.R. Sandel, M.B. Moldwin, B.W. Reinisch, Global response of the plasmasphere to a geomagnetic disturbance. J. Geophys. Res. Space Phys. 108, 1340 (2003). doi:10.1029/2003JA009987

C. Störmer, Sur les trajectories des corpuscles electrises dans l'espace sous l'action du magnetisme terrestre avec application aux aurores boreales. Arch. Sci. Phys. Nat. 24, 317-364 (1907)

M. Sugiura, Hourly values of the equatorial Dst for IGY, in Annals of the International Geophysical Year, vol. 35 (Pergamon, Oxford, Tarrytown, 1964), pp. 945-948

D. Summers, R.M. Thorne, F. Xiao, Relativistic theory of wave-particle resonant diffusion with application to electron acceleration in the magnetosphere. J. Geophys. Res. 103(A9), 20487-20500 (1998). doi:10.1029/98JA01740

S. Takahashi, T. Iyemori, M. Takeda, A simulation of the storm-time ring current. Planet. Space Sci. 38, 1133-1141 (1990)

M. Temerin, X. Li, A new model for the prediction of Dst on the basis of the solar wind. J. Geophys. Res. 107, 1472 (2002). doi:10.1029/2001JA007532 
M. Temerin, X. Li, Dst model for 1995-2002. J. Geophys. Res. 111, A04221 (2006)

M.F. Thomsen, J.E. Borovsky, D.J. McComas, M.R. Collier, Variability of the ring current source population. Geophys. Res. Lett. 25, 3481-3484 (1998)

M.F. Thomsen, H. Korth, R.C. Elphic, Upper cutoff energy of the electron plasma sheet as a measure of magnetospheric convection strength. J. Geophys. Res. 107, 1331 (2002). doi:10.1029/2001JA000148

R.M. Thorne, Radiation belt dynamics: The importance of wave-particle interactions. Geophys. Res. Lett. 37, L22107 (2010). doi:10.1029/2010GL044990

R.M. Thorne, E.J. Smith, R.K. Burton, R.E. Holzer, Plasmaspheric hiss. J. Geophys. Res. 78, 1581-1596 (1973). doi:10.1029/JA078i010p01581

F.R. Toffoletto, R.W. Spiro, R.A. Wolf, J. Birn, M. Hesse, Modeling inner magnetospheric electrodynamics, in Space Weather, ed. by P. Song, H.J. Singer, G.L. Siscoe (Am. Geophys. Union, Washington, 2001). doi:10.1029/GM125p0265

F. Toffoletto, S. Sazykin, R. Spiro, R. Wolf, Inner magnetospheric modeling with the rice convection model. Space Sci. Rev. 107, 175-196 (2003)

G. Tóth, I.V. Sokolov, T.I. Gombosi et al., Space weather modeling framework: A new tool for the space science community. J. Geophys. Res. 110(A12), A12226 (2005). doi:10.1029/2005JA011126

G. Tóth, B. van der Holst, I.V. Sokolov et al., Adaptive numerical algorithms in space weather modeling. J. Comput. Phys. 231(3), 870-903 (2012). doi:10.1016/j.jcp.2011.02.006

N.B. Trivedi et al., Geomagnetically induced currents in an electric power transmission system at low latitudes in Brazil: A case study. Space Weather 5, S04004 (2007). doi:10.1029/2006SW000282

B.T. Tsurutani, E.J. Smith, Postmidnight chorus: A substorm phenomenon. J. Geophys. Res. 79, 118-127 (1974). doi:10.1029/JA079i001p00118

N.A. Tsyganenko, Modeling the Earth's magnetospheric magnetic field confined within a realistic magnetopause. J. Geophys. Res. 100, 5599-5612 (1995)

N.A. Tsyganenko, A model of the near magnetosphere with a dawn-dusk asymmetry 1. Mathematical structure. J. Geophys. Res. 107, 12-1-12-15 (2002a). doi:10.1029/2001JA000219

N.A. Tsyganenko, A model of the near magnetosphere with a dawn-dusk asymmetry 2. Parameterization and fitting to observations. J. Geophys. Res. 107, 10-1-10-17 (2002b). doi:10.1029/2001JA000220

N.A. Tsyganenko, Data-based modelling of the Earth's dynamic magnetosphere: A review. Ann. Geophys. 31, 1745-1772 (2013). doi:10.5194/angeo-31-1745-2013

N.A. Tsyganenko, V.A. Andreeva, A forecasting model of the magnetosphere driven by an optimal solar wind coupling function. J. Geophys. Res. Space Phys. 120, 8401-8425 (2015). doi:10.1002/2015JA021641

N.A. Tsyganenko, V.A. Andreeva, An empirical RBF model of the magnetosphere parameterized by interplanetary and ground-based drivers. J. Geophys. Res. Space Phys. 121, 10786-10802 (2016). doi:10.1002/2016JA023217

N.A. Tsyganenko, T. Mukai, Tail plasma sheet models derived from Geotail particle data. J. Geophys. Res. 108(A3), 1136 (2003). doi:10.1029/2002JA009707

N.A. Tsyganenko, M.I. Sitnov, Modeling the dynamics of the inner magnetosphere during strong geomagnetic storms. J. Geophys. Res. 110, A03208 (2005). doi:10.1029/2004JA010798

N.A. Tsyganenko, M.I. Sitnov, Magnetospheric configurations from a high-resolution data-based magnetic field model. J. Geophys. Res. 112, A06225 (2007). doi:10.1029/2007JA012260

N.A. Tsyganenko, H.J. Singer, J.C. Kasper, Storm-time distortion of the inner magnetosphere: How severe can it get? J. Geophys. Res. 108(A5), 1209 (2003). doi:10.1029/2002JA009808

D.L. Turner, V. Angelopoulos, S.K. Morley, M.G. Henderson, G.D. Reeves, W. Li, D.N. Baker, C.-L. Huang, A. Boyd, H.E. Spence, S.G. Claudepierre, J.B. Blake, J.V. Rodriguez, On the cause and extent of outer radiation belt losses during the 30 September 2012 dropout event. J. Geophys. Res. Space Phys. 119, 1530-1540 (2014). doi:10.1002/2013JA019446

D.L. Turner, S.G. Claudepierre, J.F. Fennell et al., Energetic electron injections deep into the inner magnetosphere associated with substorm activity. Geophys. Res. Lett. 42, 2079-2087 (2015). doi:10.1002/ 2015GL063225

A.Y. Ukhorskiy, B.J. Anderson, P.C. Brandt, N.A. Tsyganenko, Storm time evolution of the outer radiation belt: Transport and losses. J. Geophys. Res. Space Phys. 111, A11S03 (2006). doi:10.1029/ 2006JA011690

A.Y. Ukhorskiy, M.I. Sitnov, R.M. Millan, B.T. Kress, J.F. Fennell, S.G. Claudepierre, R.J. Barnes, Global storm time depletion of the outer electron belt. J. Geophys. Res. Space Phys. 120, 2543-2556 (2015). doi:10.1002/2014JA020645

M.E. Usanova, A. Drozdov, K. Orlova, I.R. Mann, Y. Shprits, M.T. Robertson, D.L. Turner, D.K. Milling, A. Kale, D.N. Baker, S.A. Thaller, G.D. Reeves, H.E. Spence, C. Kletzing, J. Wygant, Effect of EMIC waves on relativistic and ultra-relativistic electron populations: Ground-based and Van Allen Probes observations. Geophys. Res. Lett. 41, 1375-1381 (2014). doi:10.1002/2013GL059024 
I.I. Vakulin, O.S. Grafodatskii, V.I. Degtiarev, V.I. Dovgii, G.A. Zherebtsov, The radiation environment of the geostationary orbit for magnetically quiet conditions according to data from the Raduga communication satellites. Space Res. 26, 120-126 (1988)

C. Vallat, I. Dandouras, M. Dunlop, A. Balogh, E. Lucek, G.K. Parks, M. Wilber, E.C. Roelof, G. Chanteur, H. Reme, First current density measurements in the ring current region using simultaneous multi-spacecraft CLUSTER-FGM data. Ann. Geophys. 23, 1849-1865 (2005). doi:10.5194/angeo-23-1849-2005

D. Vassiliadis, A.J. Klimas, J.A. Valdivia, D.N. Baker, The Dst geomagnetic response as function of storm phase and amplitude and the solar wind electric field. J. Geophys. Res. 104(A11), 24957-24976 (1999)

V.M. Vasyliunas, Mathematical models of magnetospheric convection and its coupling to the ionosphere, in Particles and Fields in the Magnetosphere, ed. by B.M. McCormac (D. Reidel, New York, 1970)

J.I. Vette, The AE-8 trapped electron model environment, National Space Science Data Center (NSSDC), World Data Center A for Rockets and Satellites (WDC-A-RS), National Aeronautics and Space Administration, Goddard Space Flight Center (1991)

A. Viljanen, A. Pulkkinen, R. Pirjola, K. Pajunpää, P. Posio, A. Koistinen, Recordings of geomagnetically induced currents and a nowcasting service of the Finnish natural gas pipeline. Space Weather 4, S10004 (2006). doi:10.1029/2006SW000234

C.B. Wang, J.K. Chao, C.H. Lin, Influence of the solar wind dynamic pressure on the decay and injection of the ring current. J. Geophys. Res. 108, 1341 (2003). doi:10.1029/2003JA009851

H. Wang, A.J. Ridley, H. Lühr, M.W. Liemohn, S.Y. Ma, Statistical study of the subauroral polarization stream: Its dependence on the cross-polar cap potential and subauroral conductance. J. Geophys. Res. 113, A12311 (2008). doi:10.1029/2008JA013529

H. Wang, H. Lühr, K. Häusler, P. Ritter, Effect of subauroral polarization streams on the thermosphere: A statistical study. J. Geophys. Res. 116, A03312 (2011). doi:10.1029/2010JA016236

W. Wang, E.R. Talaat, A.G. Burns, B. Emery, S. Hsieh, J. Lei, J. Xu, Thermosphere and ionosphere response to subauroral polarization streams (SAPS): Model simulations. J. Geophys. Res. 117, A07301 (2012). doi:10.1029/2012JA017656

S. Watanabe, E. Sagawa, K. Ohtaka, H. Shimazu, Prediction of the Dst index from solar wind parameters by a neural network method. Earth Planets Space 54, 1263-1275 (2002)

S. Watari, Estimation of geomagnetically induced currents based on the measurement data of a transformer in a Japanese power network and geoelectric field observations. Earth Planets Space 67, 77 (2015). doi:10.1186/s40623-015-0253-8

D.R. Weimer, Improved ionospheric electrodynamic models and application to calculating Joule heating rates. J. Geophys. Res. 110(A5), A05306 (2005). doi:10.1029/2004JA010884

D. Wen, Y. Yuan, J. Ou, X. Huo, K. Zhang, Ionospheric temporal and spatial variations during the 18 August 2003 storm over China. Earth Planets Space 59(4), 313 (2007)

H.I. West, R.M. Buck, J.R. Walton, Shadowing of electron azimuthal-drift motions near the noon magnetopause. Nat. Phys. Sci. 240, 6-7 (1972). doi:10.1038/physci240006a0

E.C. Whipple, Potentials of surfaces in space. Rep. Prog. Phys. 44, 1197 (1981). doi:10.1088/0034-4885/ 44/11/002

M. Wik, R. Pirjola, H. Lundstedt, A. Viljanen, P. Wintoft, A. Pulkkinen, Space weather events in July 1982 and October 2003 and the effects of geomagnetically induced currents on Swedish technical systems. Ann. Geophys. 27, 1775-1787 (2009)

M. Wiltberger, W. Wang, A.G. Burns, S.C. Solomon, J.G. Lyon, C.C. Goodrich, Initial results from the coupled magnetosphere ionosphere thermosphere model: Magnetospheric and ionospheric responses. J. Atmos. Sol.-Terr. Phys. 66, 1411-1423 (2004). doi:10.1016/j.jastp.2004.03.026

R.A. Wolf, Effects of ionospheric conductivity on convective flow of plasma in the magnetosphere. J. Geophys. Res. 75(25), 4677-4698 (1970)

R.A. Wolf, R.W. Spiro, S. Sazykin, F.R. Toffoletto, How the Earth's inner magnetosphere works: An evolving picture. J. Atmos. Sol.-Terr. Phys. 69, 288-302 (2007). doi:10.1016/j.jastp.2006.07.026

H.-C. Yeh, J.C. Foster, F.J. Rich, W. Swider, Storm time electric field penetration observed at mid-latitude. J. Geophys. Res. 96, 5707-5721 (1991). doi:10.1029/90JA02751

P. Yin, C.N. Mitchell, P.S.J. Spencer, J.C. Foster, Ionospheric electron concentration imaging using GPS over the USA during the storm of July 2000. Geophys. Res. Lett. 31, L12806 (2004). doi:10.1029/ 2004GL019899

E. Yizengaw, M.B. Moldwin, P.L. Dyson, E.A. Essex, Using tomography of GPS TEC to routinely determine ionospheric average electron density profiles. J. Atmos. Sol.-Terr. Phys. 69(3), 314 (2007)

D.T. Young, S. Perraut, A. Roux, C. de Villedary, R. Gendrin, A. Korth, G. Kremser, D. Jones, Wave-particle interactions near VHe1 observed on GEOS 1 and 2, 1, propagation of ion cyclotron waves in He1-rich plasma. J. Geophys. Res. 86, 6755 (1981) 
Y. Yu, V. Jordanova, S. Zaharia, J. Koller, J. Zhang, L.M. Kistler, Validation study of the magnetically self-consistent inner magnetosphere model RAM-SCB. J. Geophys. Res. 117, A03222 (2011). doi:10.1029/2011JA017321

Y. Yu, V. Jordanova, D. Welling, B. Larsen, S.G. Claudepierre, C. Kletzing, The role of ring current particle injections: Global simulations and Van Allen Probes observations during 17 March 2013 storm. Geophys. Res. Lett. 41, 1126-1132 (2014). doi:10.1002/2014GL059322

Y. Yu, V. Jordanova, S. Zou, R. Heelis, M. Ruohoniemi, J. Wygant, Modeling subauroral polarization streams during the 17 March 2013 storm. J. Geophys. Res. Space Phys. 120, 1738-1750 (2015). doi:10.1002/ 2014JA020371

Z. Yuan, Y. Xiong, Z. Qiao, H. Li, S. Huang, D. Wang, X. Deng, T. Raita, J. Wang, A subauroral polarization stream driven by field-aligned currents associated with precipitating energetic ions caused by EMIC waves: A case study. J. Geophys. Res. Space Phys. 121, 1696-1705 (2016). doi:10.1002/2015JA021804

S. Zaharia, C.Z. Cheng, J.R. Johnson, Particle transport and energization associated with substorms. J. Geophys. Res. 105(A8), 18741-18752 (2000). doi:10.1029/1999JA000407

J.J. Zhang, C. Wang, T.R. Sun, C.M. Liu, K.R. Wang, GIC due to storm sudden commencement in lowlatitude high-voltage power network in China: Observation and simulation. Space Weather 13, 643-655 (2015). doi:10.1002/2015SW001263

H. Zhao, X. Li, D.N. Baker et al., The evolution of ring current ion energy density and energy content during geomagnetic storms based on Van Allen Probes measurements. J. Geophys. Res. Space Phys. 120, 7493-7511 (2015). doi:10.1002/2015JA021533

H. Zhao, X. Li, D.N. Baker et al., Ring current electron dynamics during geomagnetic storms based on the Van Allen Probes measurements. J. Geophys. Res. Space Phys. 121, 3333-3346 (2016). doi:10.1002/ 2016JA022358 